\title{
DATOS PRELIMINARES DEL HALLAZGO \\ DE UNA SEPULTURA HUMANA \\ DEL HOLOCENO ANTIGUO EN EL ÁREA DE ZUG (TIRIS, SAHARA OCCIDENTAL)
}

\author{
PRELIMINARY DATA ABOUT THE DISCOVERY \\ OF A HUMAN TOMB FROM THE ANCIENT HOLOCENE PERIOD \\ IN THE ZUG AREA (TIRIS, WESTERN SAHARA)
}

\author{
Andoni Sáenz de Buruaga \\ $U P V / E H U$ \\ andoni.buruaga@ehu.eus \\ ORCID: 0000-0001-7496-9701
}

DOI: $10.1387 /$ veleia.18084

Resumen: Se presenta el hallazgo de un esqueleto humano, parcialmente expuesto en superficie, documentado en el fondo de una sebja interdunar situada en el erg de Azefal, en el extremo SE del Sahara Occidental. Su posición secuencial en un antiguo depósito estratigráfico y la datación absoluta de un pequeño fragmento óseo del individuo inhumado, precisan su cronología en una fase avanzada del Holoceno antiguo, concretamente a mediados del IX milenio calB.P. El dato conlleva una alta relevancia científica pues, en el momento actual de la investigación, constituye la referencia antropológica y sepulcral más antigua del Holoceno del Occidente del Sahara.

Palabras clave: Antropología, Holoceno antiguo, Sahara Occidental, Sepultura.

Abstract: A human skeleton was discovered, partially exposed on the surface, documented at the bottom of an interdune saline plain («sebja») located at «erg de Azefa» in the SE zone of the Western Sahara. Its sequential position in an old stratigraphic deposit and the absolute dating of a small bone fragment from the buried individual, allow for a precise chronology in the late ancient Holocene period, specifically in the mid part of the 9th millennium, calB.P. This fact has major scientific relevance because by now it constitutes the oldest anthropological and burial reference from the Holocene period in the Western Sahara.

Keywords: Anthropology, Ancient Holocene period, Western Sahara, Tomb.

Recibido: 16-01-2017

Definitivo: 20-01-2017 


\section{Presentación}

Fruto de las labores de prospección arqueológica y paleoclimática llevadas a cabo en la XX Campaña de Investigaciones Arqueológicas, Medioambientales y Culturales en el Sahara Occidental (del 29 de enero al 27 de febrero de 2016), se produjo el hallazgo de una sepultura humana en el espacio fisiográfico del erg de Azefal. La actuación se articulaba en el marco del proyecto de investigación y cooperación cultural que venimos realizando de forma sistemática, desde 2005, en los «territorios liberados» de la República Árabe Saharaui Democrática (RASD) y que hemos focalizado especialmente en torno a la región meridional del Tiris ( $c f$. Sáenz de Buruaga 2008, 2010 y 2014; Sáenz de Buruaga y Arruabarrena 2015).

El Azefal, en el extremo más suroriental del territorio saharaui, constituye un alargado campo de dunas, de orientación NE-SW y más de $500 \mathrm{~km}$ de trazado longitudinal, que comparten Mauritania y el Sahara Occidental.

No ha sido hasta 2012 en que hemos podido comenzar a trabajar puntualmente en el interior del erg: compaginando, desde entonces, su inspección — siempre en tramos de breve duracióncon la efectuada habitualmente en otras áreas del Tiris entendidas como más seguras o de menor riesgo personal. Por diversas circunstancias - fundamentalmente ajenas al planteamiento científico del proyecto, y más bien asociadas directamente a la inestabilidad geopolítica de la región-, se venía aplazando sucesivamente nuestro propósito. Afortunadamente, al final de 2011 conseguíamos el imprescindible permiso administrativo, con la consiguiente autorización militar y su cobertura elemental de seguridad, para iniciar el reconocimiento metódico de algunos tramos del mismo. En consecuencia, desde 2012 a 2016 hemos destinado una parte de las 5 campañas de invierno a rastrear diferentes áreas del campo de dunas (fig. 1).

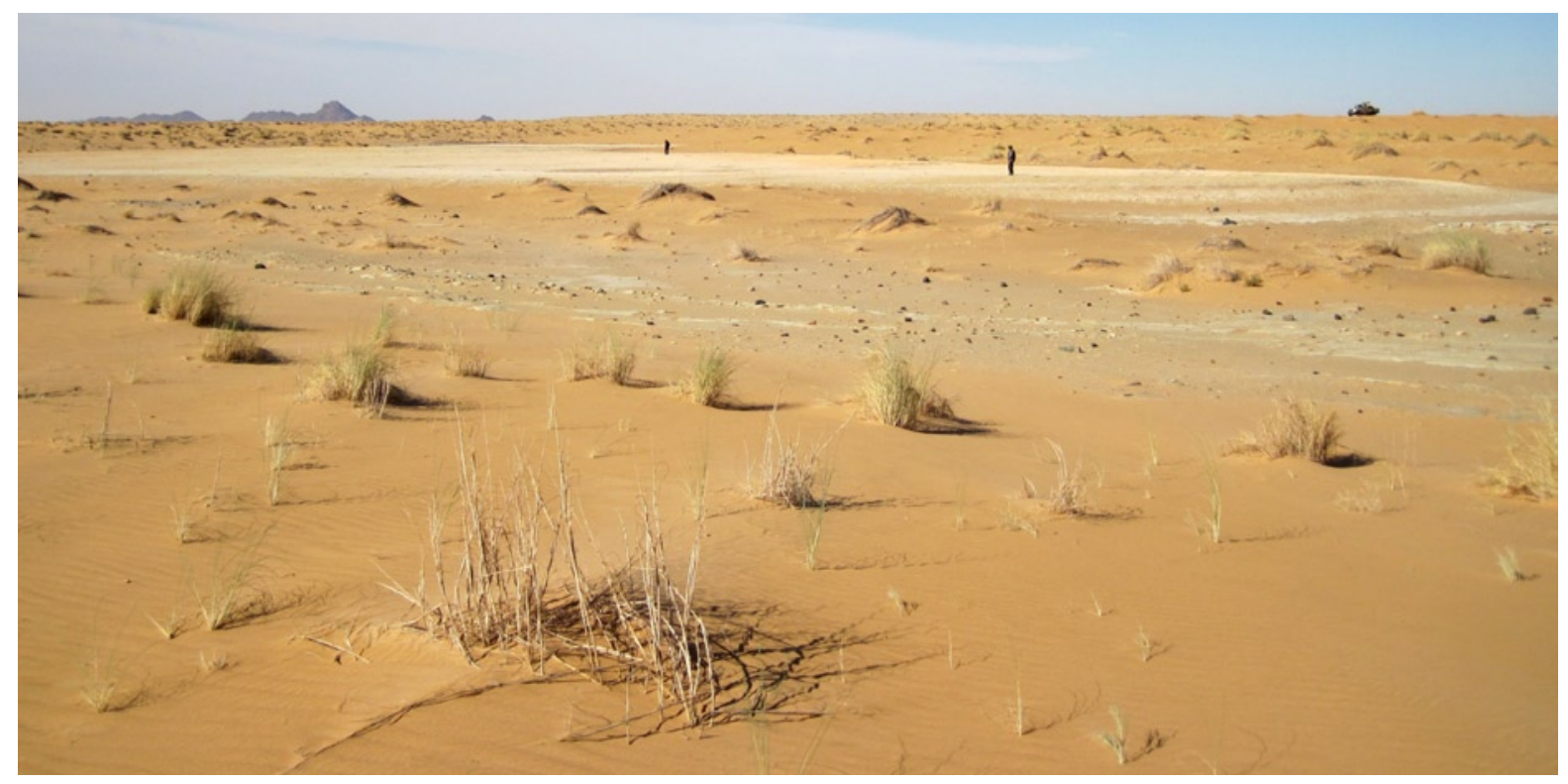

Figura i. Perspectiva general de una parte de la planicie dunar emplazada al E de las montañas de Adakmar (al fondo de la imagen), en el erg de Azefal, inspeccionada en la campaña de investigaciones arqueológicas y medioambientales de febrero de 2016. En primer término, uno de los tramos de la Sebja Planicie Adakmar E-1, fondo de depresión en la que se localizó la sepultura humana 
Podemos afirmar que, a pesar del limitado espacio reconocido — dentro de los cerca de $7.000 \mathrm{~km}^{2}$ de superficie que ocupa en las tierras saharauis-, los resultados han sido tan fructíferos que no dudamos en valorar a este particular contexto geográfico como uno de los espacios más ricos del Sahara Occidental, cuantitativa y cualitativamente, en testimonios sociales y paleoambientales de la Prehistoria del Holoceno. No en vano, de las 1.188 fichas redactadas sobre el terreno en el Tiris — de las que 1.060 son de contenido arqueológico y 128 de interés paleoclimático y medioambiental—, un total de $358(30,1 \%)$ se localizan en el interior del erg de Azefal y en sus áreas periféricas más inmediatas, repartiéndose en 311 arqueológicas — con especial significación de todas aquellas expresiones (hábitats, monumentos líticos, estaciones artísticas rupestres, etc.) genéricamente vinculadas con el desarrollo de la tradición cultural neolítica- y 47 paleoclimáticas - en forma, preferentemente, de depósitos de travertinos lacustres pertenecientes a antiguos fondos de lagos holocenos.

El hallazgo en superficie de la sepultura que aquí vamos a ocuparnos y, muy especialmente, su estimación cronológica directa en torno al IX milenio calB.P. que, a juzgar por los datos de que disponemos, la convertirían, en estos momentos, en la referencia antropológica y sepulcral más antigua del episodio geo-climático del Holoceno ( $c a .12 .000$ calB.P.-hoy) en todo el Occidente del Sahara (Sahara Occidental, Mauritania, N de Malí, W de Argelia y S de Marruecos), nos obligan a presentar, cuando menos $-\mathrm{y}$ al margen de diferentes estudios especializados que puedan acometerse en el futuro- - un inicial y breve esbozo del descubrimiento y sus circunstancias, y unas primeras valoraciones del hecho, merced a su trascendencia científica.

\section{LOCALIZACIÓN, CONTEXTO DEL HALLAZGO Y ACTUACIONES EMPRENDIDAS SOBRE EL TERRENO}

El hallazgo se produjo el día 11 de Febrero de 2016 en el curso de una puntual misión exploratoria por el sector suroccidental saharaui del erg de Azefal: en concreto, en torno a la planicie dunar que se extiende al E de las montańas de Adakmar, relieves que determinan una parte del límite territorial meridional del Sahara Occidental con Mauritania ${ }^{1}$.

De manera más precisa, el lugar en donde se llevó a cabo el descubrimiento forma parte de una amplia depresión interdunar en cuyo fondo se advierten varios tramos de una gran sebja, parcelados entre sí por depósitos de dunas, a la que hemos identificado en términos generales como «Sebja Planicie Adakmar E-1» (fig. 2). En un segmento oriental de esta formación hidrográfica localizábamos, de forma accidental, un esqueleto expuesto en buena parte superficialmente. Sus coordenadas geográficas, mediante "gps» de lectura métrica, se ajustan a los valores: $\mathrm{X}=589918$; $\mathrm{Y}=2369431$; $\mathrm{Z}=205$ [28Q]. Un marco territorial adscrito administrativamente al Sahara Occidental, situado unos $14 \mathrm{~km}$ al E.NE de las montañas de Adakmar y otros $21 \mathrm{~km}$ al S de Zug y su célebre sebja (fig. 3).

\footnotetext{
1 El equipo regular de trabajo de esa Campaña de Investigaciones en el Tiris (Sahara Occidental), de febrero de 2016, estuvo integrado por: A. Sáenz de Buruaga, H. Mohamed Ali, J.M. Arruabarrena, D. Mohamed Mberek, J. Alberdi, A. Abdi Ali y H. Badadi Ali. Además de agradecer la labor desarrollada por el grupo de estudiosos, aprovechamos la ocasión para hacerla extensiva a las instituciones que vienen posibilitando la ejecución
}

de nuestro Proyecto de investigación y cooperación cultural en el Sahara Occidental: a la Consejería de Educación, Política Lingüística y Cultura del Gobierno Vasco, a la Universidad del País Vasco (UPV/EHU) y a los distintos organismos de la RASD implicados en el apoyo y sostén de esta experiencia sobre el terreno (Presidencia de la República, Ministerio de Cultura, Ministerio de Defensa y Dirección Nacional de Protocolo). 


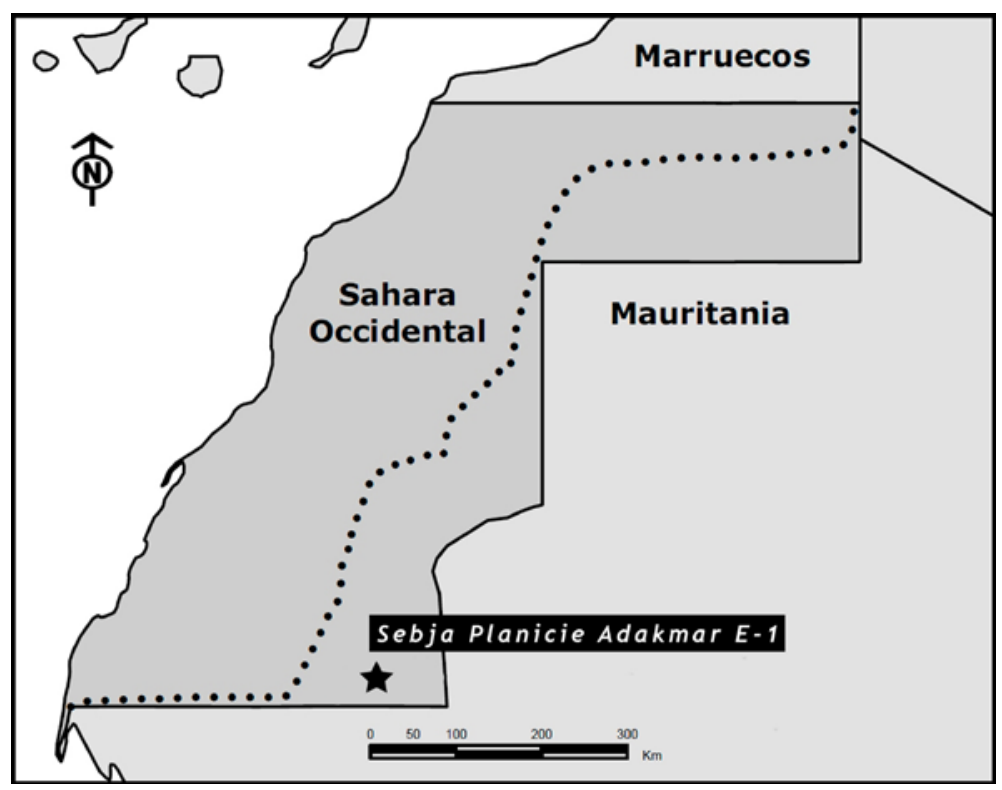

Figura 2. Situación cartográfica de la Sebja Planicie Adakmar E-1 en el extremo SE del Sahara Occidental: al E del trazado del «muro defensivo marroqui" (con linea de puntos) y en el marco de los "territorios liberados» de la RASD

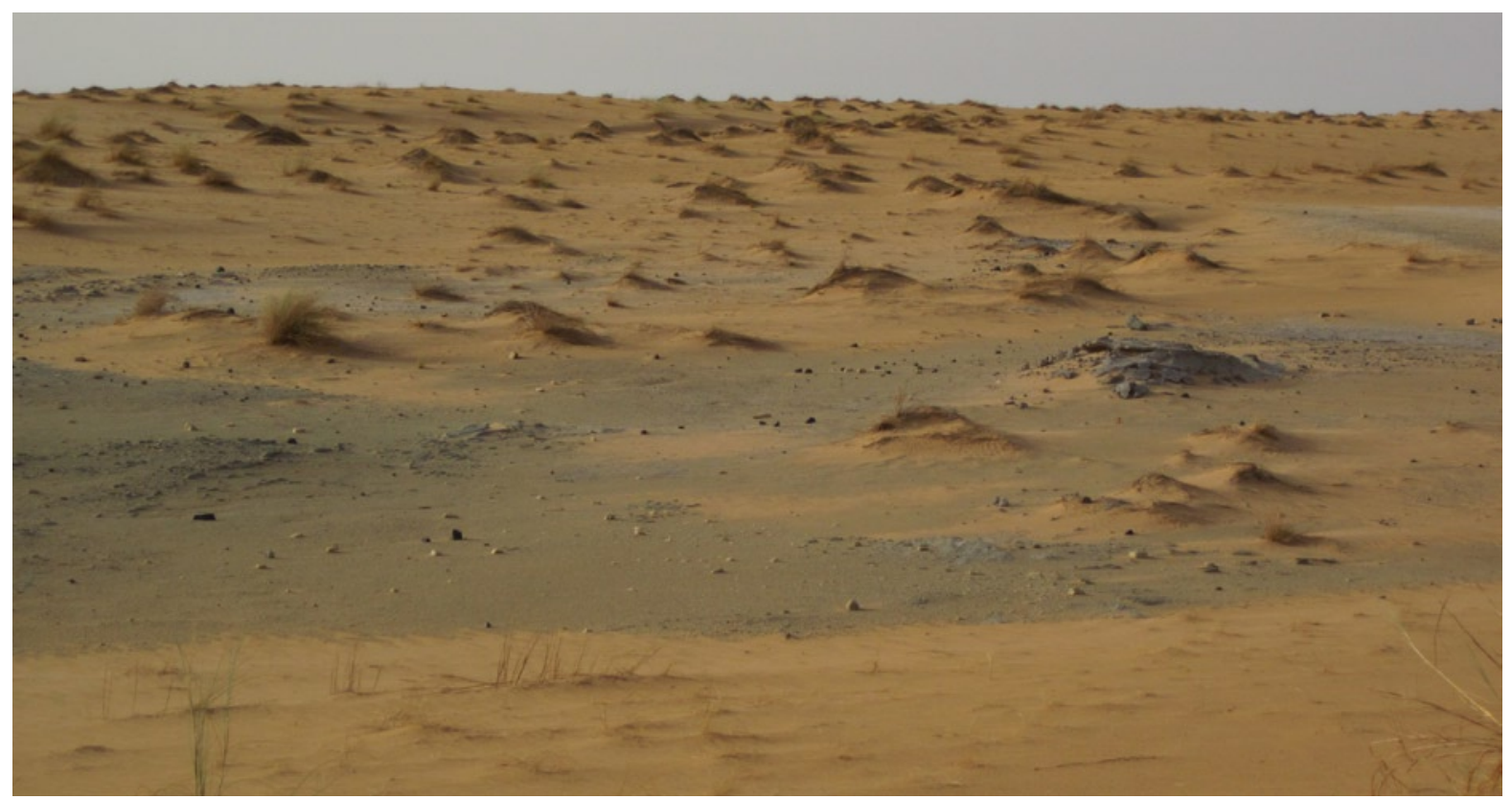

Figura 3. Detalle del segmento de sebja interdunar en el que se halló el esqueleto. En la parte media de la imagen, y algo hacia la derecha, mota residual con un depósito de travertinos, muy próxima al punto del descubrimiento antropológico 
El esqueleto se encontraba aislado y parcialmente desmantelado, depuesto en superficie sobre un pequeño y tenue amontonamiento de arenas residuales que habían prevalecido asombrosamente, a modo de mota terrera aislada, al flujo erosivo del contexto hidrográfico en que se hallaba y cuyos efectos eran generalizados en todo el espacio circundante (fig. 4).

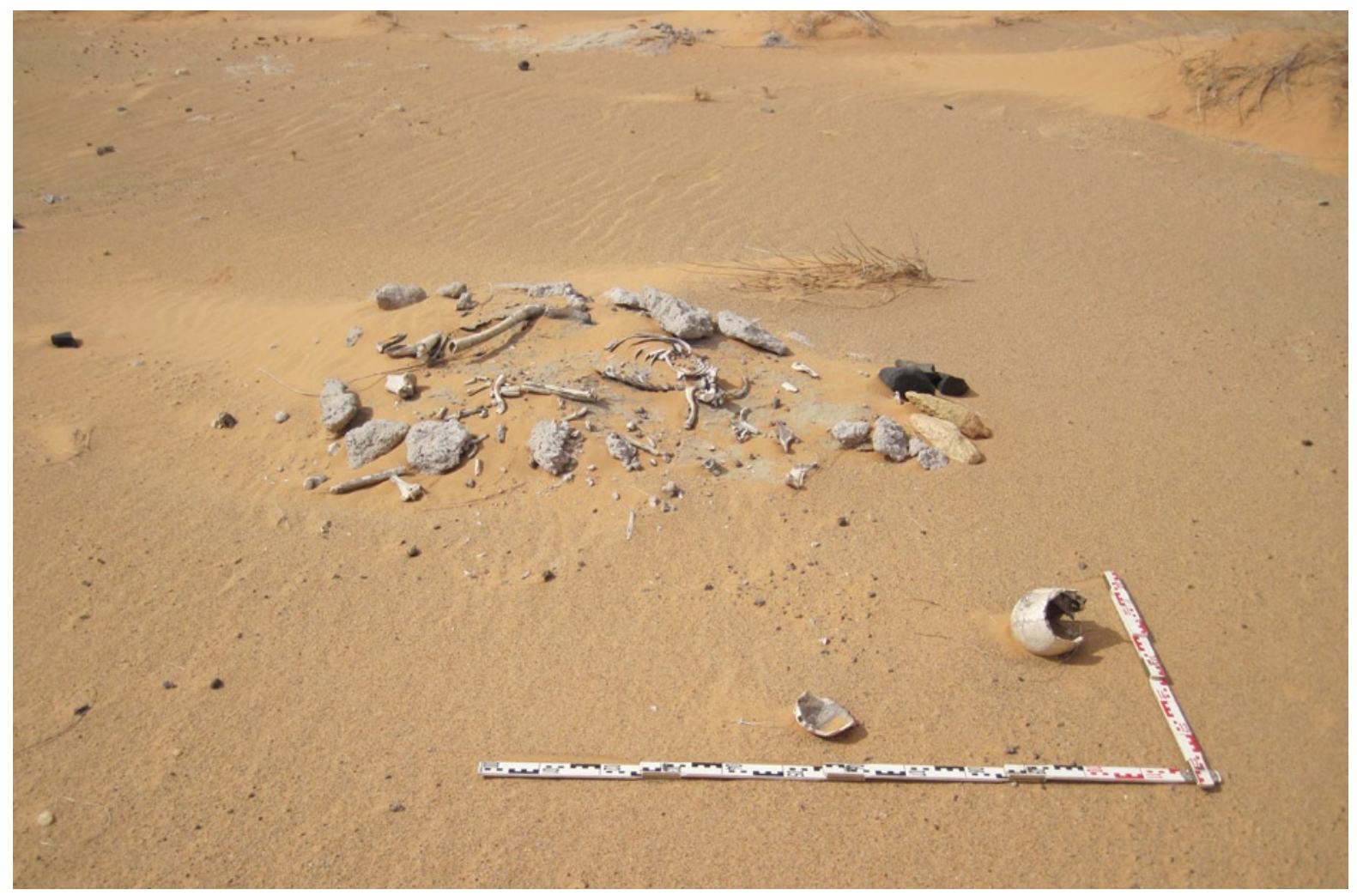

Figura 4. El esqueleto de Adakmar en el momento de su descubrimiento.

Se advertía de visu cómo una parte de la estructura anatómica del cuerpo se encontraba parcialmente embutida en la matriz de arenas carbonatadas de coloración gris-verdosa clara que definía su asiento sedimentario. Una circunstancia que habría tenido su incidencia positiva en el mantenimiento y conservación agrupada de buena parte de los restos humanos.

Además, algunos gestos singulares observados en la disposición de los huesos — como, por ejemplo, la marcada posición flexionada de las extremidades inferiores - invitaban a sugerir fórmulas rituales de cierta antigüedad, más, en principio, no podían entenderse como argumentos sólidos y determinativos de una expresión funeraria "antigua». Era necesario contar con más pruebas resolutivas.

Por otra parte, el grueso del esqueleto se encontraba delimitado perimétricamente —y, en algún punto, más interiormente-, de forma intencional, por una serie mayoritaria de bloques extraídos de un depósito de travertinos cementado, situado a pocos metros del mismo, y complementariamente de algunos puntuales bloques de granito y diorita. Esas rocas se habían colocado superficialmente —en ningún caso se advirtió su incrustación en el depósito arenoso de base-, en tiempos 
recientes, probablemente con el propósito de evitar la disgregación y el desparrame de los huesos y asimismo, de alguna manera, como "gesto sepulcral» de respeto y pudor, otorgando al cadáver de una especie de recinto sepulcral accidental. Esta moderna y eventual «sepultura», preferentemente a base de bloques de travertinos, era de morfología ovalada y rondaba los $2 \times 1 \times 0,25 \mathrm{~m}$ (fig. 5).

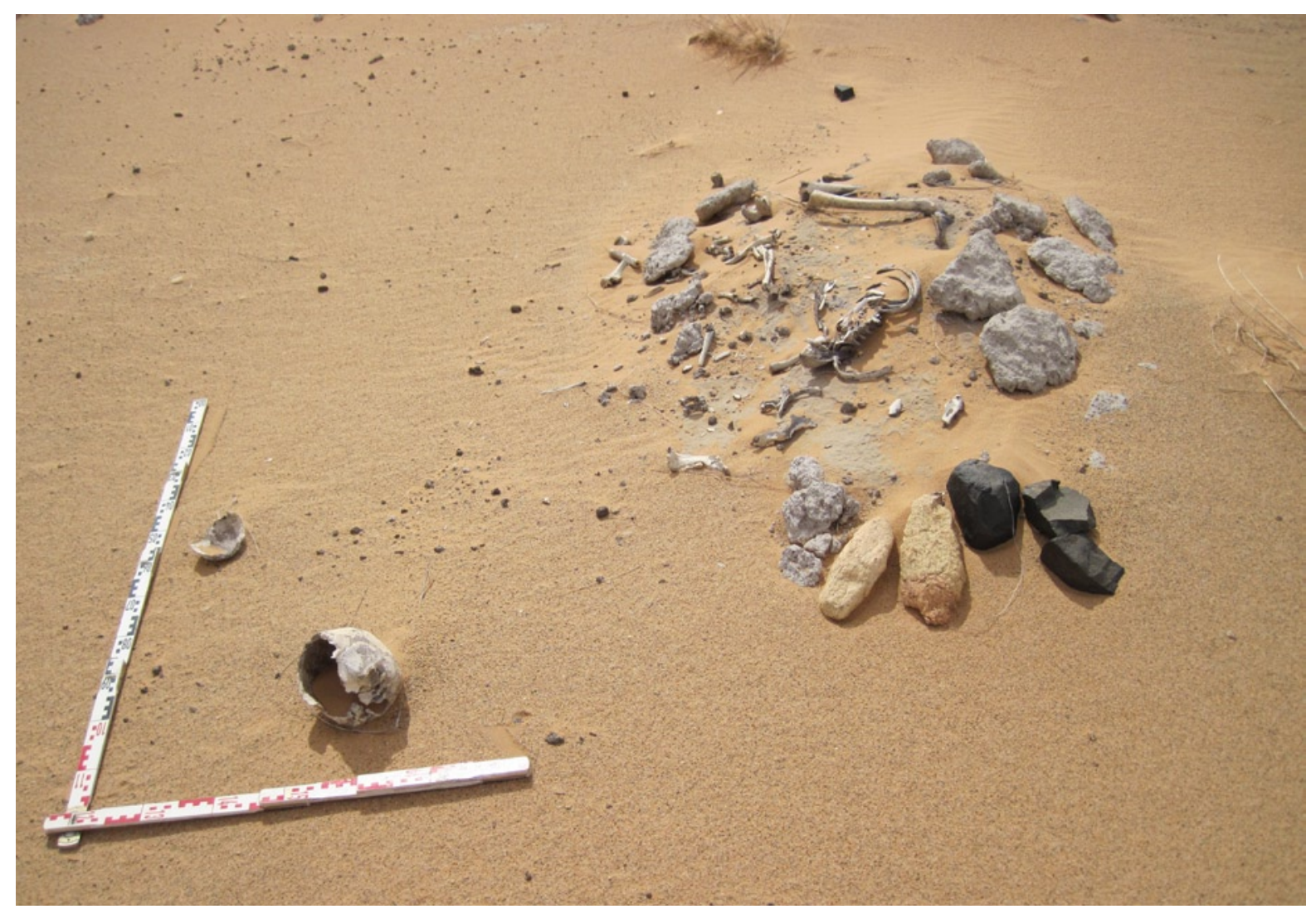

Figura 5. Protección del esqueleto, en época reciente, mediante bloques mayormente de travertinos, y alguno más puntual de granito y diorita, a modo de eventual recinto funerario

Mas, al margen de la intencionalidad sepulcral del cadáver y de su antigüedad, se imponía sobre el terreno una urgente y pronta - por falta de tiempo disponible- reflexión acerca de proceder o no, seguidamente, a su recuperación como sujeto patrimonial. Ante la imprevista situación planteada con un hallazgo de estas características y el evidente riesgo de destrucción o desaparición definitiva del testimonio antropológico, por una parte, y sin poseer por nuestro lado de los instrumentos y medios de trabajo más adecuados para su rigurosa y detenida excavación, sin la infraestructura elemental para garantizar su conservación y sin poder contar con el tiempo mínimo — además de la imposibilidad logística - para solventar estas deficiencias operativas, por otra, debíamos tomar una decisión de alcance en ese mismo momento. Básicamente, teníamos 2 alternativas: o lo dejábamos, más o menos, protegido, para una ocasión posterior, de cara a poder excavarlo detenidamente, o procedíamos, sin más preámbulos, directamente a su rescate a través de una más que pronta intervención de urgencia. 
La primera opción — que aparentemente pudiera ofrecerse como sensata y reflexiva- nos pareció - por nuestro particular conocimiento y experiencia en el medio sahariano en que nos movemos - muy arriesgada, insegura y altamente problemática. En consecuencia, optamos más pragmáticamente por proceder a la recuperación del esqueleto de la forma más ordenada posible: operando progresivamente a la extracción de los huesos desde la parte superior del cuerpo a la inferior, e intentando mantener en bloque las partes anatómicas mayores en función de su grado de conexión (fig. 6).
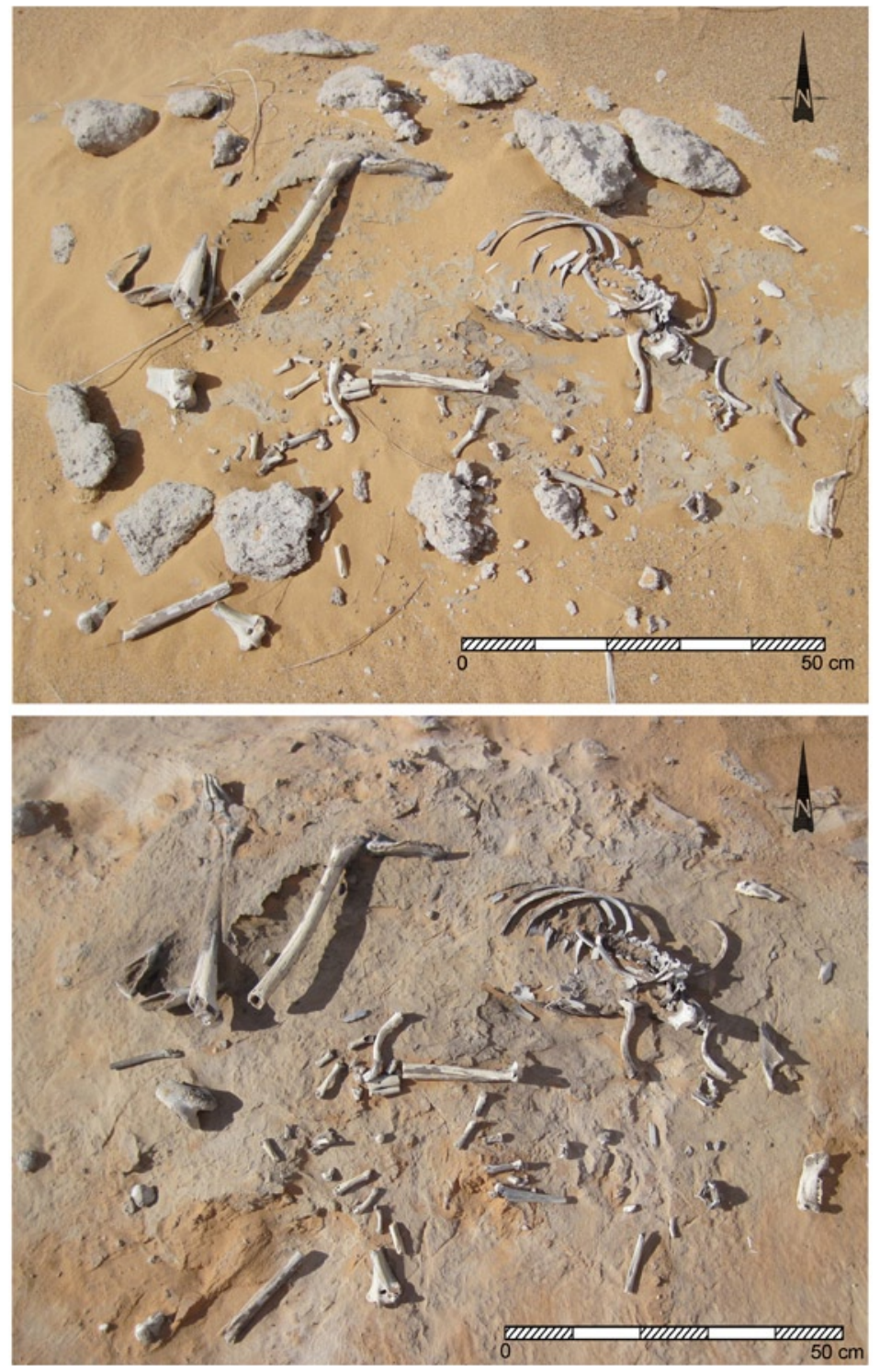

Figura 6. Presentación inicial del esqueleto (arriba), e imagen del mismo tras el levantamiento de los bloques rocosos de moderna delimitación sepulcral y de su elemental limpieza superficial (abajo) 
De esta suerte, el conjunto óseo fue distribuido en 6 lotes de piezas que se introdujeron en sendas bolsas de plástico dobles, debidamente etiquetadas y rotuladas. Se diferenciaron las siguientes unidades: 1) huesos varios superficiales; 2) huesos craneales sueltos; 3) cavidad torácica; 4) pelvis y fémures; 5) tibias y peronés; $y, 6)$ tarsianos y metatarsianos.

La intervención arqueológica de urgencia se llevó a cabo la misma jornada de su hallazgo, el 11 de febrero de 2016.

Toda la serie se depositó, a la conclusión de la campańa de campo, en el cuarto depósito que tenemos asignado para estos menesteres en la Base militar de Agüenit (Sahara Occidental).

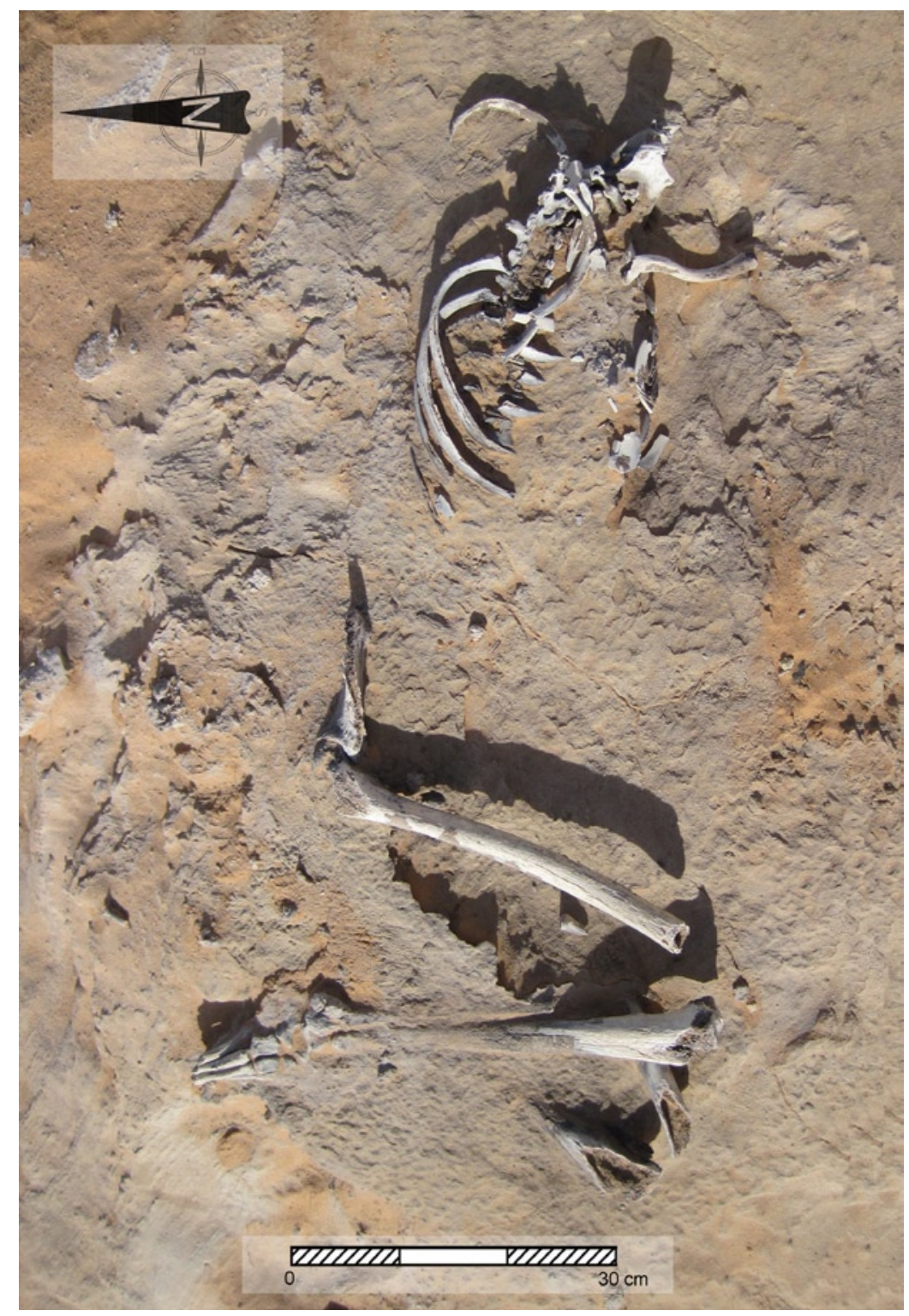

FIGURA 7. Dispositivo funerario ritual del individuo, una vez retirados los huesos superficiales sueltos 


\section{EL PROCESO DE EXTRACCIÓN DE LOS RESTOS ANATÓMICOS Y LA CONSTATACIÓN DE UN ANTIGUO GESTO SEPULCRAL}

A medida que se fue avanzando en el proceso de extracción de los restos óseos, fueron progresivamente clarificándose las conjeturas y dudas planteadas sobre su antiguo carácter sepulcral. Una serie de pruebas y razonamientos fundamentan incontestablemente su intencionalidad funeraria (fig. 7). Entre estos deben contemplarse, al menos, los siguientes:

\section{La posición de las partes del cuerpo}

Si ésta no se puede precisar para la cabeza —al encontrase desplazada a algunos metros del cadáver-, ni para las extremidades superiores — en buena parte ausentes o disgregadas del cuerpo y esparcidas superficialmente-, sí resulta determinativa en otros bloques corpóreos. Así, el tórax se halla mayormente en posición dorsal, con un tenue desplazamiento hacia el lateral izquierdo, es decir, reposando ligeramente sobre parte de su costado izquierdo (fig. 8). Y, junto e ello, los miembros de las extremidades inferiores aparecen en clara y marcada posición flexionada o contraída sobre el lateral izquierdo.

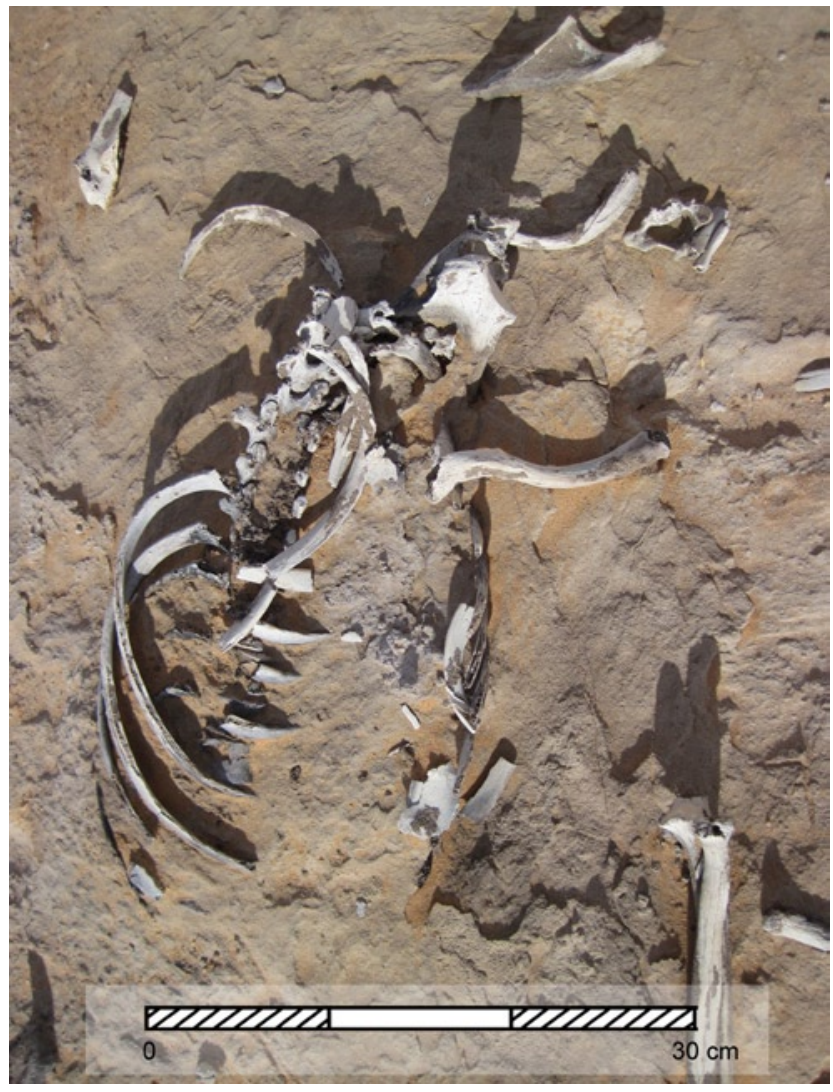

Figura 8. Detalle de la cavidad torácica encajada parcialmente en el depósito arenoso carbonatado de asiento. Pueden apreciarse, de forma nitida, los efectos de una combustión en buena parte del armazón torácico 
De ello, pues, podemos precisar la posición general del cuerpo, como decúbito fronto-lateral y extremidades inferiores flexionadas (fig. 9).

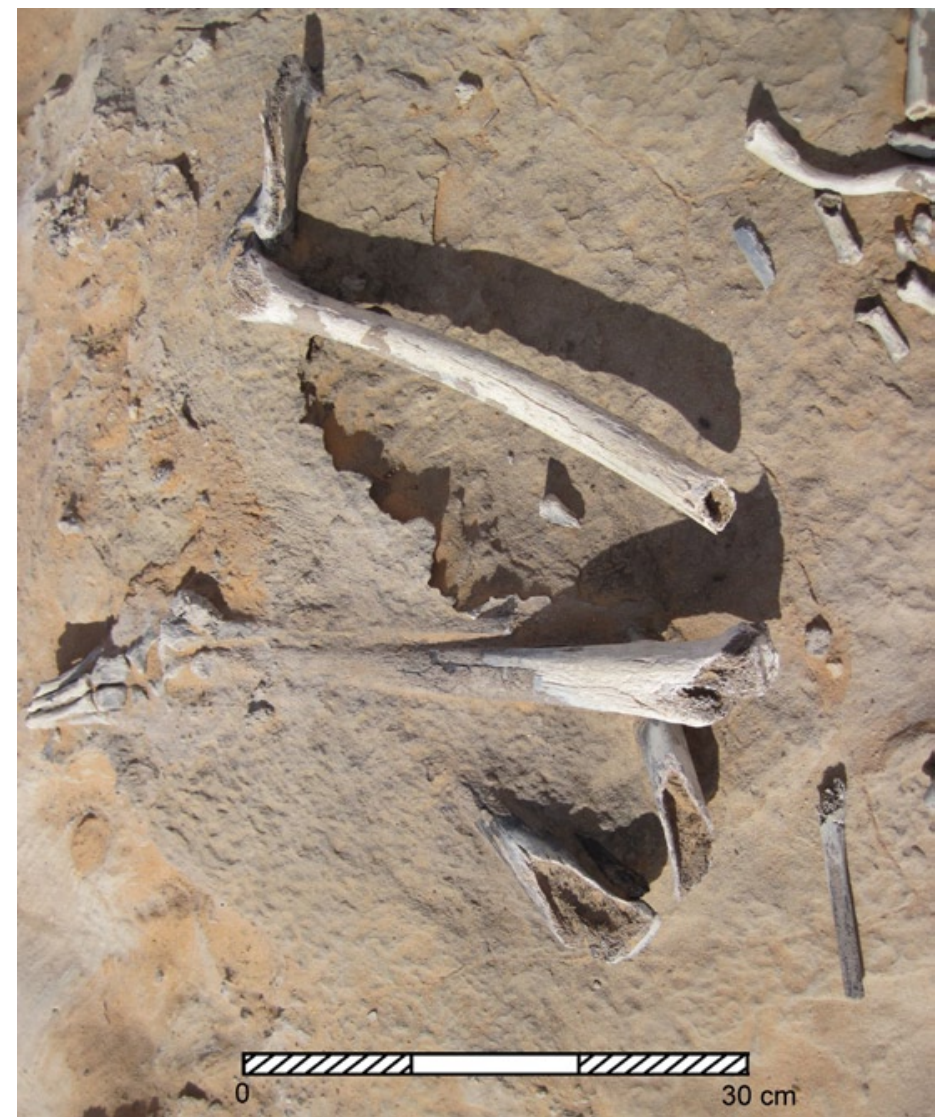

Figura 9. Conjunto anatómico integrado por pelvis, fémur, tibia, peroné y huesos del pie. Se advierte cómo la flexión angular de las extremidades inferiores es muy marcada

\section{La orientación del esqueleto}

El cadáver se halla orientado de E (parte superior) a W (parte inferior), y mirando hacia el S.

\section{El carácter de inhumación primaria}

A pesar de que el esqueleto muestra algunos restos desarticulados y disgregados superficialmente, como hemos mencionado con anterioridad, una parte considerable del mismo presenta los huesos en conexión anatómica. Y si a ello - y a las apreciaciones sobre la posición y orientación del individuo - se ańade el hecho de poder apreciar in situ buena parte de los huesos de los pies, puede afirmarse sin riesgo su rango de inhumación primaria (fig. 10). 


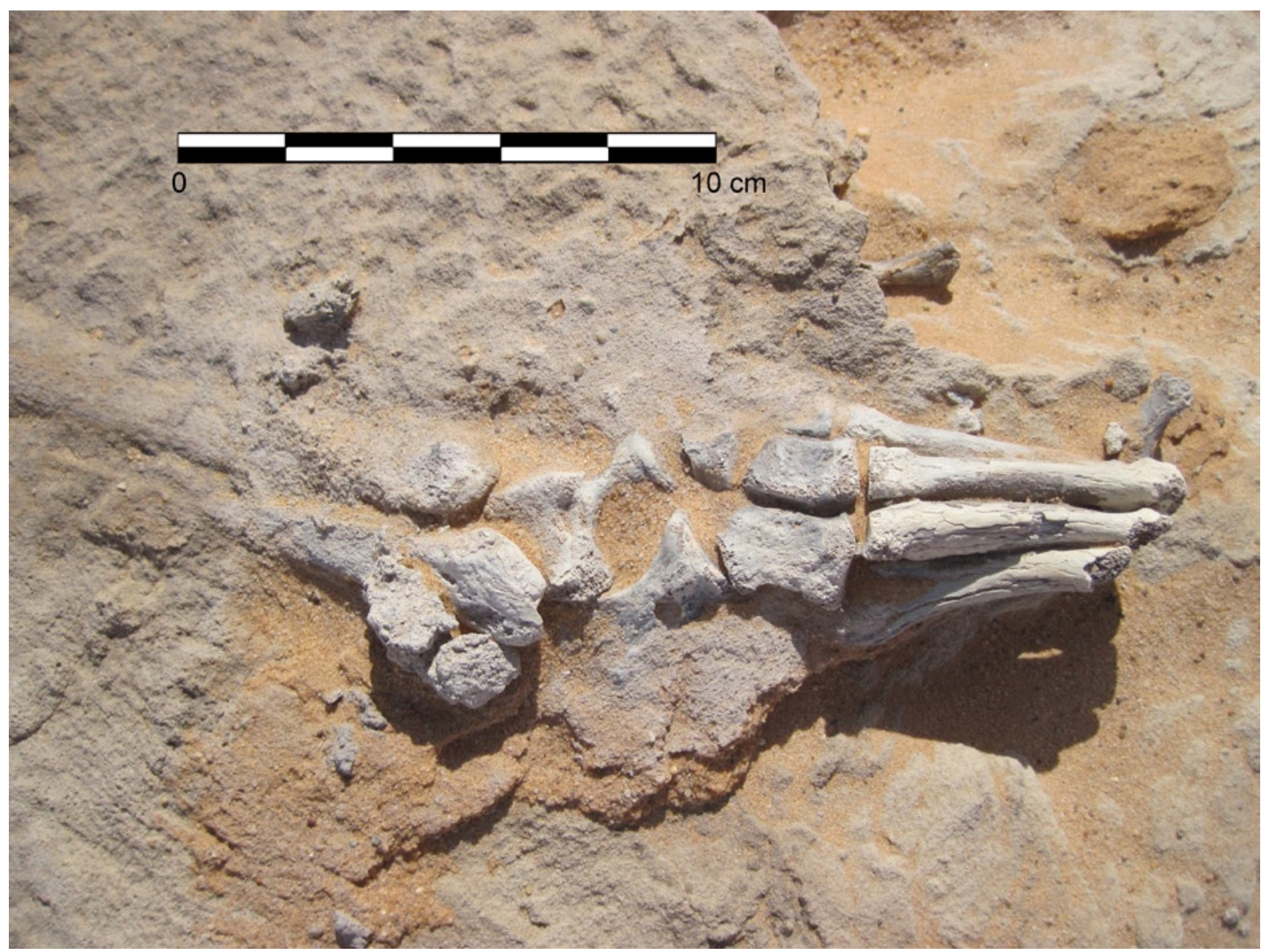

FIGURA IO. Estructura anatómica articulada del pie

\section{La deposición del cadáver en fosa o cubeta}

Desde una perspectiva teórica, el hecho de que el esqueleto se haya mantenido en gran parte de forma bastante agrupada, invitaría a contemplar acaso, y entre otros, que algún elemento externo al mismo hubiera podido facilitar esa cohesión de los huesos, como por ejemplo, pudiera derivarse de su deposición en una oquedad practicada sobre el suelo, e, incluso, de una envoltura en la que pudiera haberse encontrado contenido.

La constatación en el proceso de excavación de los restos de una concavidad en el terreno sobre la que se apoyaba el cuerpo nos hacía intuir la existencia de una fosa o, en su caso, de una cubeta con menor fondo, intencional y previamente practicada como nicho sepulcral de asiento.

Hemos de retener, pues, como verosímil que la posición del cadáver se haya realizado ritualmente sobre una fosa o cubeta poco profunda excavada para la ocasión sobre el suelo arenoso.

En concordancia con esta idea, hay que señalar que la oquedad de la sepultura se muestra colmatada aparentemente por el mismo tipo de sedimento (en fracción, grano y color) que el del contexto pedológico en el que se asienta: lo cual sugeriría que, tras ser excavada y depositado en ella el cadáver, se cubrió seguidamente con una tierra equiparable, probablemente con la misma extraída. 
Y a ello se une un similar grado de carbonatación que el del depósito primario externo: una alteración diagenética que resultaría, en consecuencia, ulterior a la inhumación. En cualquier caso, no hay duda que tanto el colmatado de la concavidad como la precipitación de carbonatos sobre la matriz arenosa, habrían favorecido posteriormente el mantenimiento de los huesos en posición anatómica.

Ciertamente, algunas considerables partes de la fosa o cubeta habían ya desaparecido del contexto del hallazgo, junto al depósito de tierra circundante, a causa de acciones erosivas, fundamentalmente de génesis hidrológica, sobre ese tramo de la sebja. Sin duda, el sector en el que resulta más evidente la oquedad practicada se corresponde con el fondo o base de la sepultura, en el que parecen dibujarse puntualmente los límites y suelo de la cavidad. En buena lógica, la profundidad y dimensiones de la misma, resultan imposibles de precisar, pudiendo proponerse en el mejor de los casos unas medidas de mínimos - y de orientación sobre el terreno básica- en función de las dimensiones aportadas directamente por el esqueleto: cuya superficie rondaba en planta los $1 \times 0,65 \mathrm{~m}$ y su disposición cardinal era E-W.

\section{El tratamiento del cadáver por el fuego como parte de un posible ritual funerario}

El proceso de extracción de los restos antropológicos nos puso de manifiesto el inequívoco tratamiento por el fuego del esqueleto. Un hecho que, de forma muy especial, resultaba más que evidente en la parte inferior de la cavidad torácica, así como en la superficie de contacto entre esta y el suelo de la oquedad sepulcral (fig. 11). Por el contrario, en la parte superior de la caja torácica los efectos crematorios eran bastante menos nítidos y más imprecisos: quizás, fruto de su mayor exposición superficial, o a consecuencia del posible ritual ensayado. Y es que, al margen de alteraciones postdepositacionales más marcadas sobre la parte más expuesta del individuo, el hecho invita a considerar la práctica de una fórmula ritual merced a la cual el cadáver bien pudiera haber sido depositado sobre algún lecho de materiales aún incandescentes, previamente organizado sobre el fondo de la fosa o cubeta, con lo que la zona más profunda es la que hubiera recibido los efectos más agudos de la combustión.

Estos 5 testimonios constituyen, en nuestra opinión, un cúmulo de hechos arqueofunerarios convergentes que enfatizan y refuerzan la definición sepulcral del depósito antropológico. Un enterramiento indudablemente preislámico, del que, al margen de su encaje en un genérico contexto prehistórico postpaleolítico, poco más pudiera precisarse, en principio, sobre su antigüedad.

En este sentido, en el proceso de excavación de la sepultura e inhumación conservados, no se advirtió resto alguno de mobiliario funerario (industrias, objetos de adorno, restos de fauna, etc.) del que pudiera inducirse una aproximación crono-cultural en términos relativos. De igual manera, ninguna estructura de piedra, mayor o menor, ha podido ser identificada junto al cadáver, en el entorno de la sepultura, ni en el contexto sedimentario inmediato. Así, pues, no hay constancia de depósitos de materiales arqueológicos o aparentemente de sustancias asociadas directamente al difunto, ni presencia alguna de restos macroscópicos de materias colorantes en marco de la fosa o cubeta (fig. 12). 


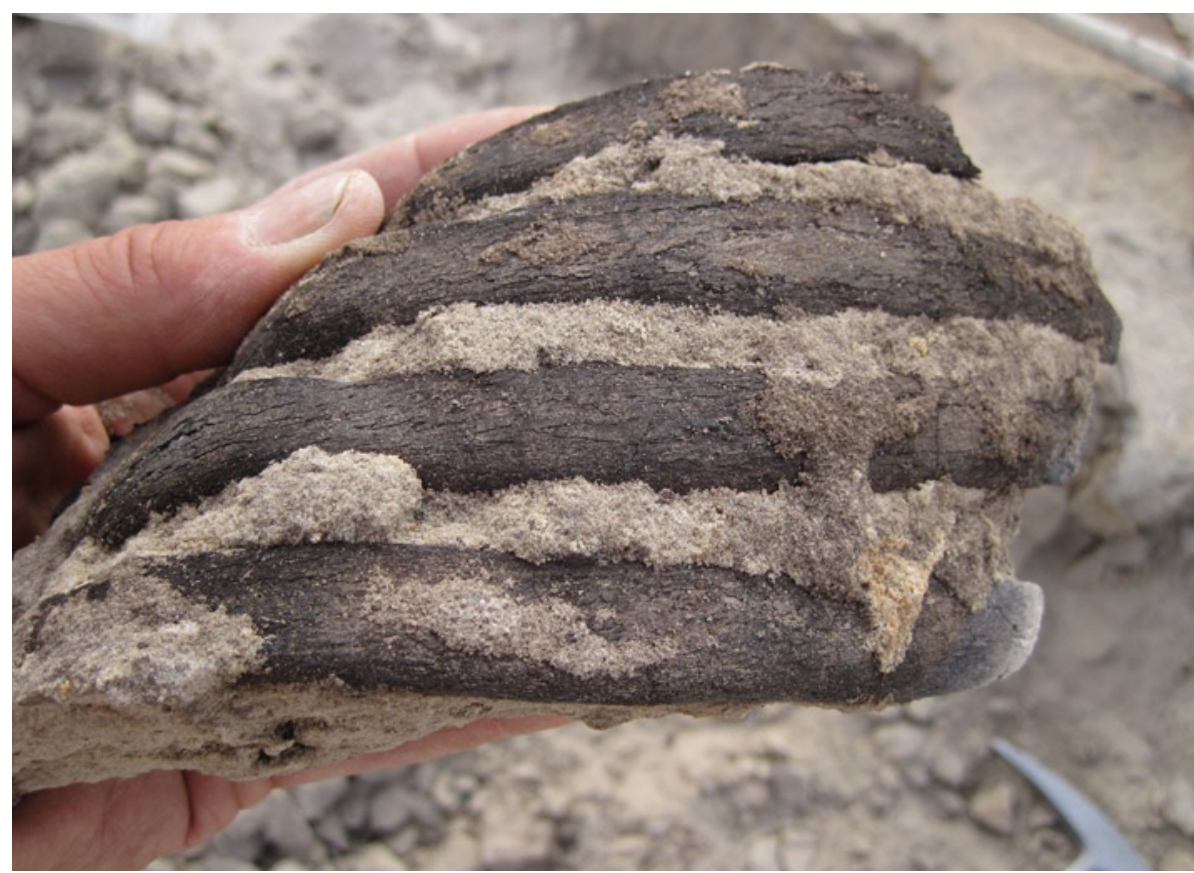

Figura i i. Detalle de la alteración por el fuego de la parte inferior de la cavidad torácica del cadáver

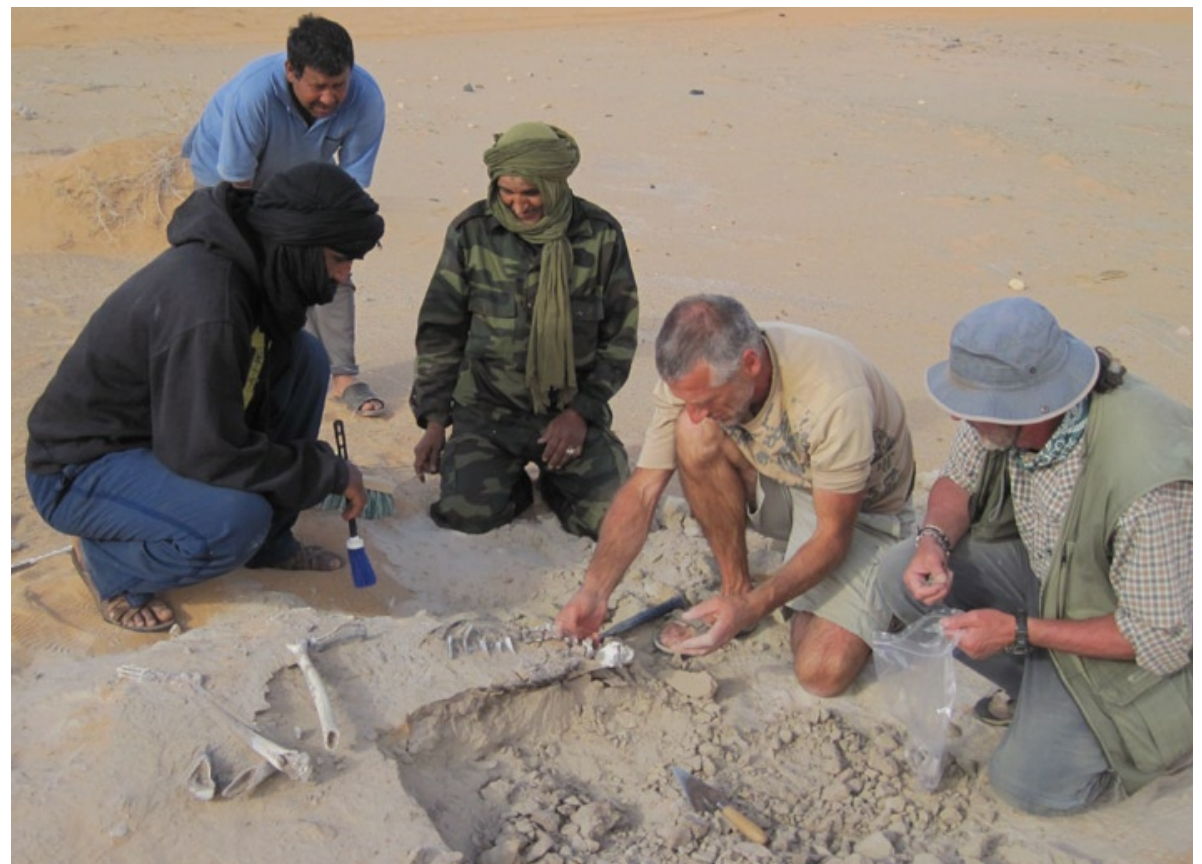

Figura I2. Una parte del proceso de recuperación de urgencia de los restos anatómicos de la sepultura de Adakmar 
Por otra parte, resultaría más que especulativo el intentar razonar una posible relación entre el contexto sepulcral y algunas industrias prehistóricas, de genérica tradición neolítica, que han sido recuperadas en otras áreas de esa depresión en cuyo fondo se halla la Sebja Planicie Adakmar E-1 (fig. 13).
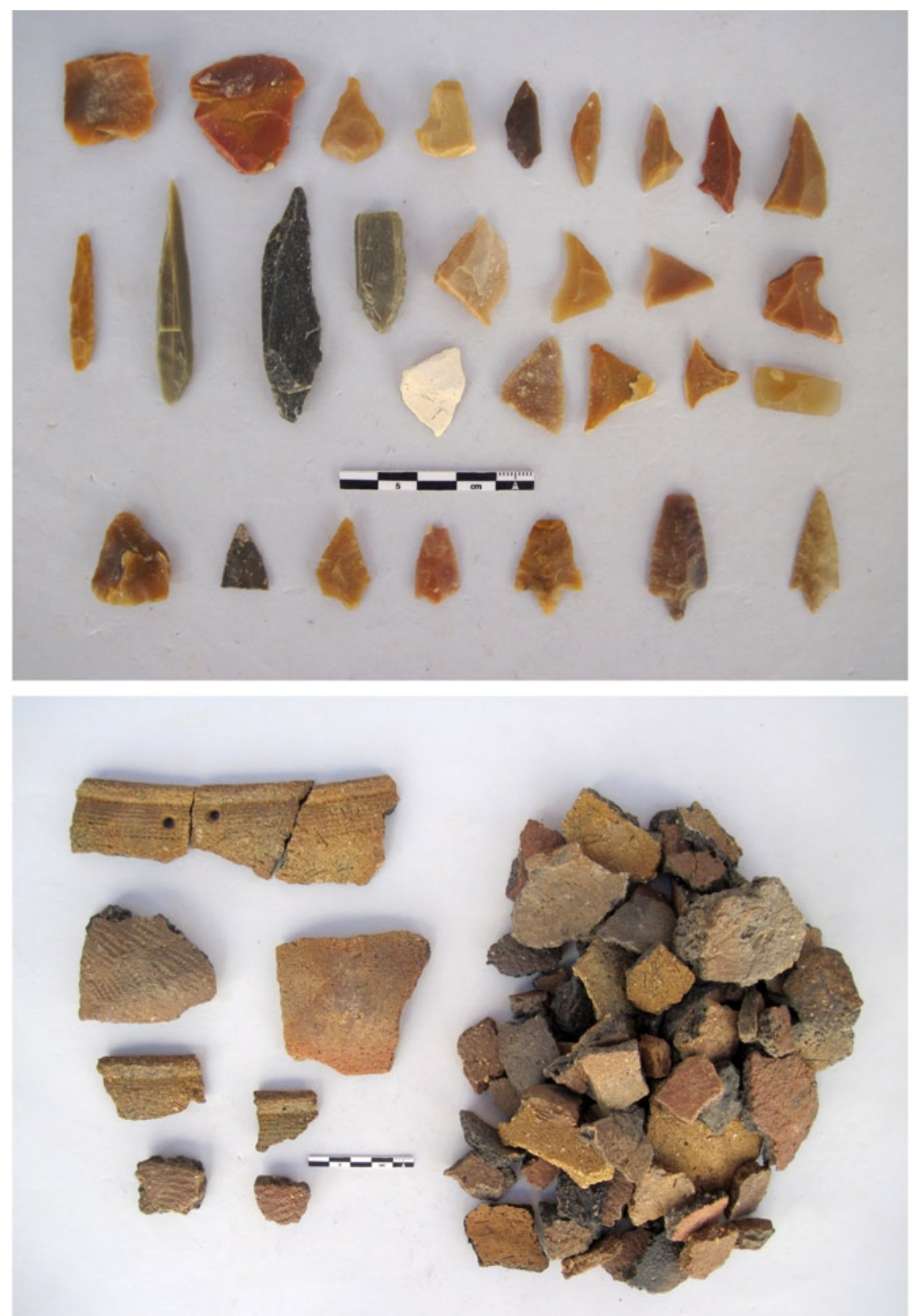

FigURA I 3. Muestra de representativos utensilios liticos tallados y de restos cerámicos a mano recuperados en superficie en la inspección de alguno de los segmentos interdunares de la Sebja Planicie Adakmar E-1 (Zug, Azefal, Sahara Occidental) 
Y, por último, convendría incidir en el hecho de que se trata de una sepultura individual primaria y, en principio, aislada: sin deberse descartar, hipotéticamente, que pudiera formar parte de un conjunto funerario acaso oculto bajo los potentes depósitos de travertinos cercanos. De ser así, una profundización de los trabajos de investigación sobre el terreno pudiera conducir al hallazgo de nuevas inhumaciones y, en el caso favorable, a procurar un salto cualitativo de alta envergadura en el conocimiento de las prácticas funerarias y de las costumbres mortuorias de un tramo del pasado prehistórico del Holoceno del Occidente del Sahara francamente oscuro.

\section{LA ANTIGÜEDAD DE LA SEPUltURA HUMANA Y LA GÉNESIS DEL DEPÓSITO SEDIMENTARIO ENCAJANTE}

En principio, toda sepultura que se halla muy cerca de la superficie plantea razonables dudas en relación a su contemporaneidad con el depósito en que se encuentra.

En nuestro caso, esa sospecha resulta más que verosímil, tanto por la caracterización sedimentológica y posición secuencial del depósito de arenas encajante, por un lado, como por los resultados de los análisis cronométricos directamente del esqueleto y de un depósito de travertinos que recubre al estrato de arenas citado en el área inmediata a la sepultura, por el otro.

Unos datos que ayudan a precisar la cronología de la inhumación y corroboran sin ambages la antigüedad de la sepultura humana.

En efecto, contamos con una datación radiométrica del depósito de travertinos masivo grisáceo (Munsell 10YR7/1), compacto y cementado, que se superpone directamente a la serie arenosa de base en cuyo tramo superior se sitúa la sepultura humana. Esa formación travertínica, que en algún caso ronda los $40 \mathrm{~cm}$ de potencia, muestra macroscópicamente aportes vegetales incrustados en su matriz, y zonalmente ofrece acumulaciones de caparazones de gasterópodos de agua dulce, entre los que predomina el género Biomphalaria sobre los más secundarios Bulinus y Melanoides. Y, precisamente, un análisis C14-AMS de esas conchas ha procurado la fecha de $6.700 \pm 35$ B.P. (Poz-81145), situándose su horquilla temporal más representativa en términos calibrados entre 5.674-5.546 calB.C., es decir, aproximándose su valor medio a 7.560 cal.B.P. Una data ésta que geo-climáticamente habría que asimilarla con el desarrollo de una fase inicial del Holoceno medio (ca. 7.800-5.500 calB.P.) (fig. 14).

Tras un neto contacto erosivo bajo esta formación de travertinos, se accede a un depósito de arenas carbonatadas, de coloración grisáceo-verdosa clara (Munsell 2.5Y7/2), que ronda $1 \mathrm{~m}$ de potencia y casi llega a alcanzar el sustrato rocoso gneisíaco de base. La definición granulométrica y morfoscópica de la fracción fina, y su particular disposición laminar oblicua advertible en algunos tramos internos, posibilitan definirla como una formación arenosa de origen eólico que, por su posición secuencial, debiera relacionarse con el último episodio árido del Pleistoceno superior, u Ogoliense del Occidente del Sahara (ca. 24.000-16.000 calB.P.): anterior, en cualquier caso, a la mejora climática que se vislumbra desde $c a .13 .000$ calB.P. y que, de alguna forma, preludia la llegada del Holoceno (fig. 15).

Probablemente, este depósito arenoso se encuentra complementariamente asociado a un proceso ulterior de gleificación, o de precipitación química reductora de causalidad hidrológica. Este episodio de alteración pedológica, bien pudo acontecer en algún tramo del Holoceno antiguo, ciertamente con posterioridad a la práctica de la inhumación, y anterior a la formación travertínica del Holoceno medio que cubre el estrato a techo. 


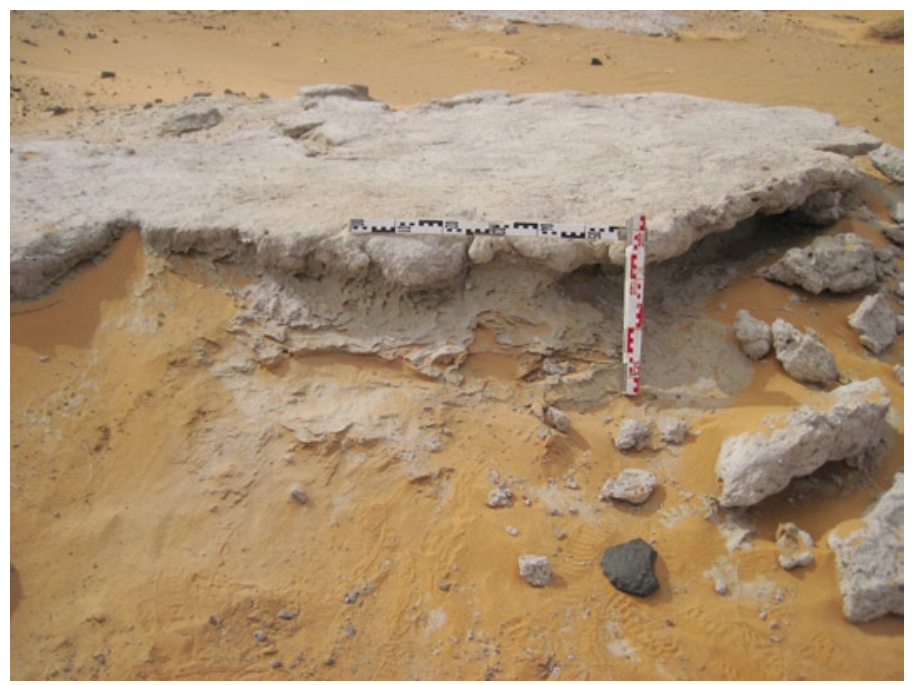

Figura i4. Depósito superior de travertinos, del inicio del Holoceno medio, que debia cubrir el estrato subyacente con la sepultura de Adakmar. De esa porción de formación rocosa subhorizontal, por otra parte, se debieron extraer la mayoría de los bloques rocosos utilizados para delimitar y cubrir parcialmente el esqueleto en tiempos recientes

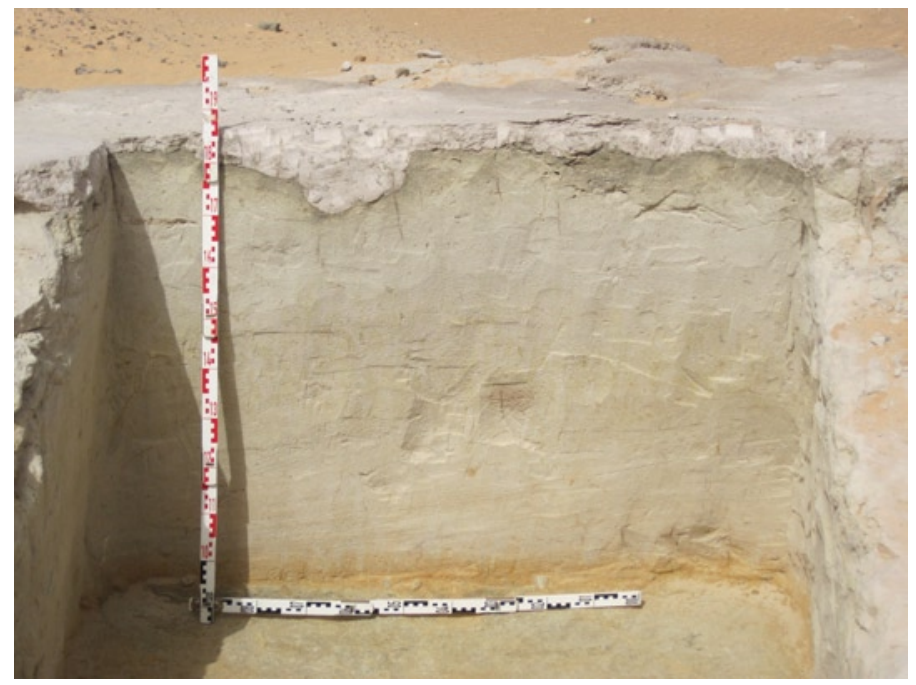

Figura i 5. Perspectiva frontal del perfil estratigráfico documentado en un sondeo practicado en el entorno inmediato a la sepultura. Delimitado a techo por la formación de travertinos cementados y a muro por una ligera capa arenosa inmediatamente sobre el suelo rocoso de gneis de base, se encaja el notable depósito de arenas carbonatadas, probablemente de génesis en el episodio árido del Ogoliense (ca. 24.000-16.000 calB.P.), en cuyo tramo superior se practicó la antigua inhumación holocena 

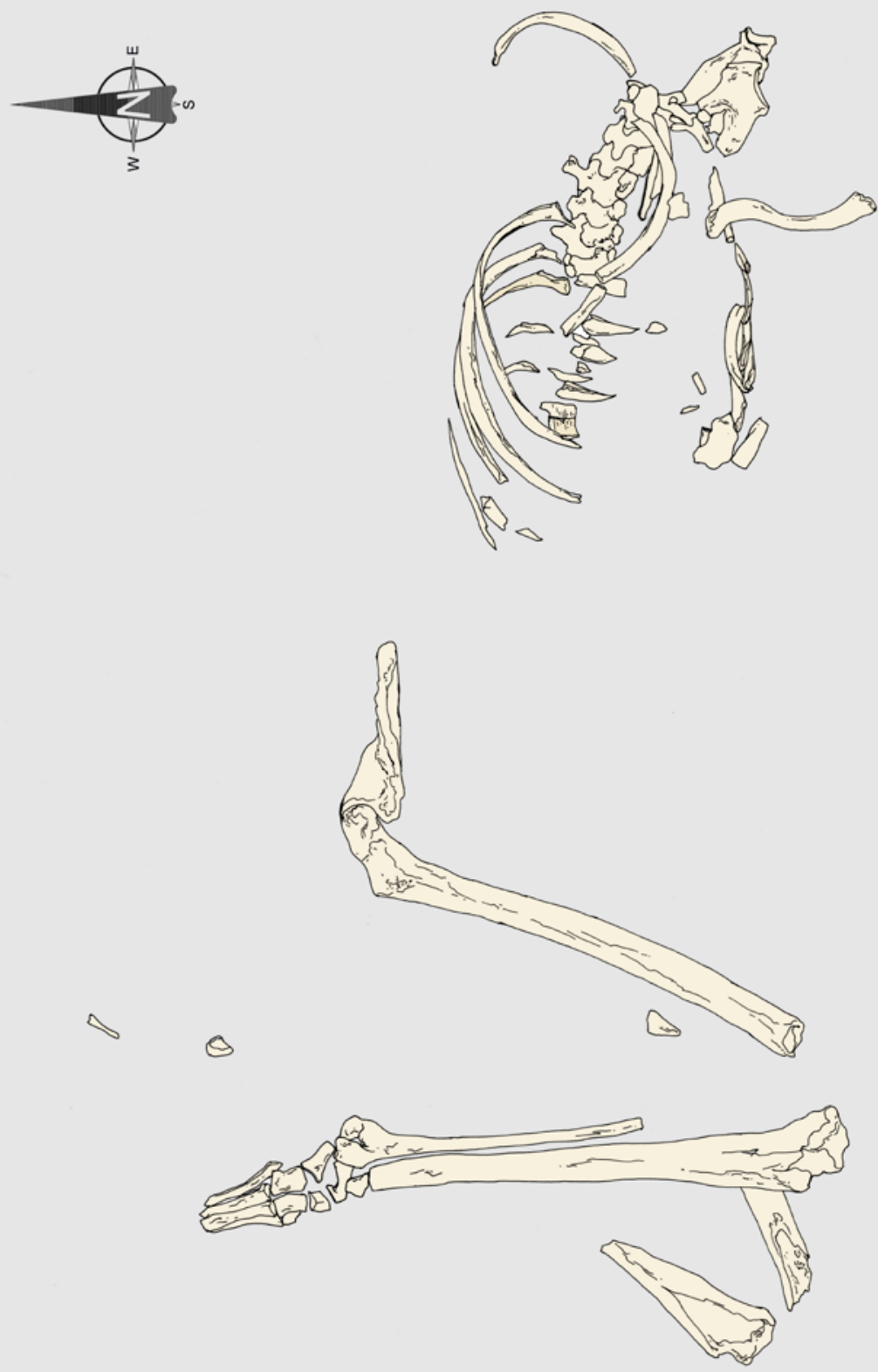

Figura i 6. Representación gráfica contrastada de las partes anatómicas externas del enterramiento del Holoceno antiguo de la Sebja Planicie Adakmar E-1, datado a mediados del IX milenio calB.P. 
Y, tal como señalábamos, sobre el tramo superior de este depósito de arenas se materializó la sepultura humana: probablemente de un varón de edad adulta. El análisis C14-AMS de un pequeño fragmento carbonizado de costilla proveniente de la parte más inferior de la cavidad torácica, en contacto ya con el suelo de la fosa o cubeta, aportó la fecha de $7.720 \pm 50$ B.P. (Poz-80958) ${ }^{2}$, lo que situaría su rango de calibración más certero en 6.641-6.467 calB.C., o con un valor medio en torno a 8.504 calB.P. Un registro temporal que se correspondería con las fases avanzadas del Holoceno antiguo (ca. 12.000-7.800 calB.P.) (fig. 16).

\section{La inhumación de Adalmar en el contexto sepulcral prehistórico del Sahara Occidental Y MARCO DESÉRTICO CIRCUNDANTE}

La datación directa del esqueleto humano de Adakmar a mediados del IX milenio calB.P. es, sin duda alguna, una dato de alta relevancia científica. De hecho, constituye el testimonio antropológico y la sepultura funeraria más antigua del Holoceno, no ya del Sahara Occidental, sino del vasto marco espacial del Occidente del Sahara (Sahara Occidental, Mauritania, N de Malí, W de Argelia y $S$ de Marruecos). Y, junto a ello, su encuadre geo-climático en el Holoceno antiguo puede resultar de muy alta trascendencia para comenzar a rastrear y clarificar, con pruebas científicas fósiles, las direcciones y flujos migratorios de las más antiguas ocupaciones humanas del Occidente sahariano, y que debieron de acaecer sensiblemente con el progresivo advenimiento de la actualidad climática del Holoceno.

En el estado actual del conocimiento científico, el gesto sepulcral humano de Adakmar supone, en cierta manera, un isolat, en la medida en que, de momento, no puede correlacionarse directamente con otros datos antropológicos espacialmente cercanos y de rango cronológico relativamente próximo. Baste apuntar que las referencias más afines temporalmente habría que rastrearlas en contextos del Capsiense del N de África ( $c f$. El Hajraoui et al. 2012; Aoudia-Chouakri 2013), a más de $2.000 \mathrm{~km}$ lineales de distancia, y con algunos puntuales sepulcros del Sahara central y meridional, como Tin Hanakaten (Tassili N'Ajjer, Argelia) (Aumassip 1984; Aumassip y Heim 1989) y la espectacular necrópolis de Gobero (Níger) (Sereno et al. 2008), a más de $2.500 \mathrm{~km}$ en cada caso. De ahí, ese aislamiento científico al que venimos de aludir.

En el extenso espacio del Occidente del Sahara, la datación de una de las sepulturas en fosa de Izriten (Tarfaya, SW de Marruecos) — a unos $900 \mathrm{~km}$ lineales al N de nuestro hallazgo_-, practicada sobre una antigua duna, proporcionó la fecha, en valores convencionales, de $6.100 \pm 120$ B.P. (Grébénart 1975a, 198; Petit-Maire, Charon y Ortlieb 1979, 28), cuya estimación media en términos calibrados, rondaría los 6.970 calB.P. Hasta ahora constituía la fecha antropológica más antigua del Holoceno del Occidente sahariano. Su descubridora, N. Petit-Maire, afirmaba constatar ciertos rasgos anatómicos que emparentaban a esos individuos con el grupo morfológico fósil de «Mechta El Arbi» o «Mechta-Afalou» y a las poblaciones más antiguas de las Islas Canarias: ex-

\footnotetext{
2 Según nos precisó amablemente el Dr. T. Goslar, responsable del Poznan Radiocarbon Laboratory (Foundation of the Adam Mickiewicz University, Poland) en el que se llevó a cabo la analítica cronométrica, el hecho de que el hueso estuviera carbonizado posibilitó su tratamiento como carbón. En este sentido, debería tenerse presente por cautela que quizás
}

una parte de ese carbón preservado en el resto óseo pudiera aglutinar aportes del combustible utilizado, y en el caso que éste se tratara de madera cabría presumir que el valor obtenido del C14 llegara a ser ligeramente algo más viejo que el del propio hueso: mas, eso sí, solamente unas pocas décadas (in litteris, 09.06.2016). 
plicando su presencia en esas latitudes como resultado de un proceso migratorio litoral continuo que desde hace 12.000 a 6.500 años se habría extendido desde Túnez al Cabo Juby (Petit-Maire 1979a, 74; Dutour y Petit-Maire 1996). Anatómicamente, el esqueleto de esta "tumba 1» de Izriten se ha hecho corresponder a un sujeto femenino: una joven adulta de unos 20-25 años de edad y con una estatura de en torno a 1,50 m (Petit-Maire y Dutour 1996, 123).

La nueva data de Adakmar hace retrotraer ahora, pues, en más de 1.500 años la antigüedad de los testimonios fósiles de restos humanos a lo largo del desarrollo de la primera mitad del Holoceno. Lo que, sin duda, hará plantear nuevas perspectivas en el seno de las hipótesis que se han venido barajando en relación al origen del poblamiento en esta región sahariana del NW de África (fig. 17).

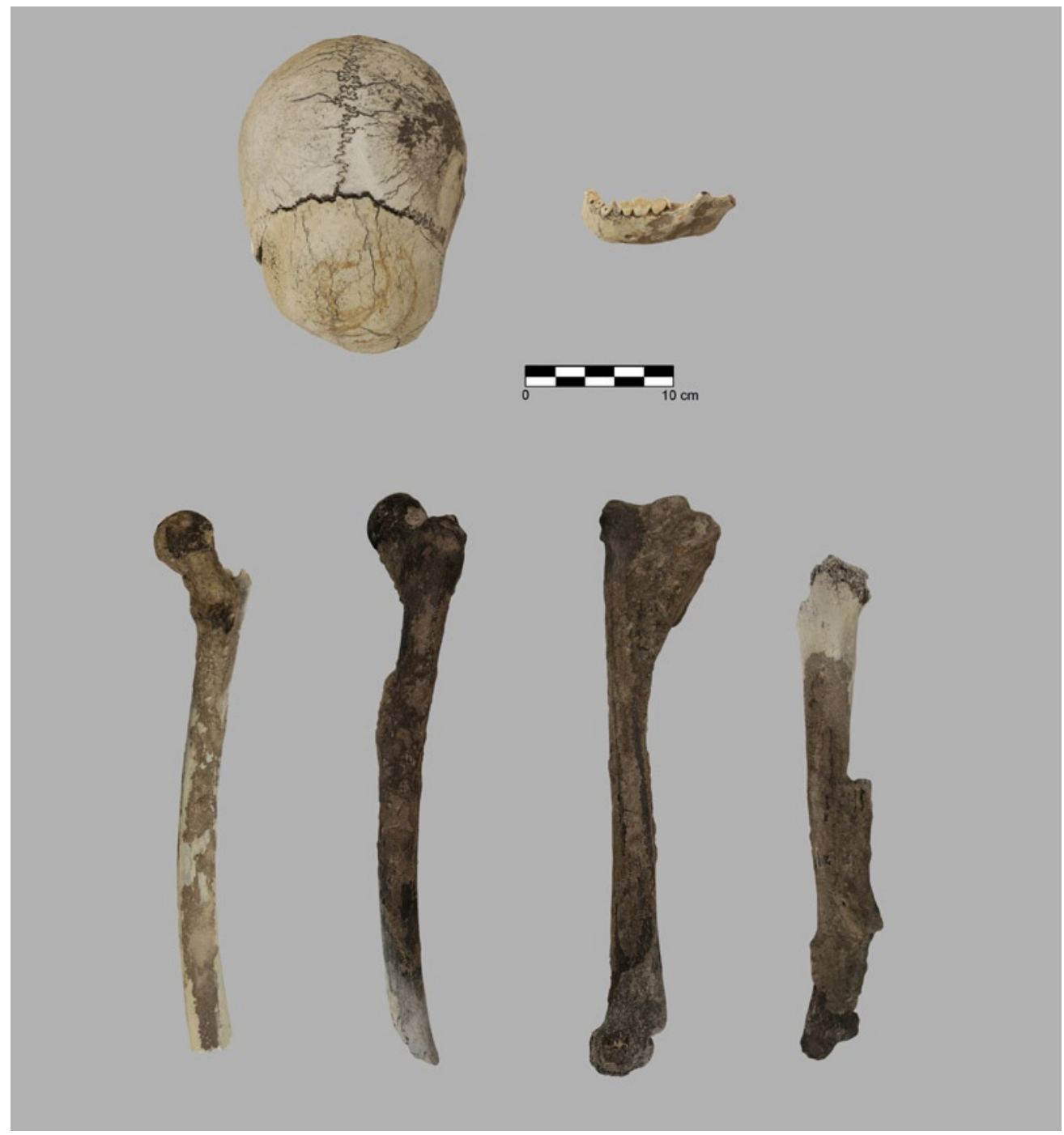

FiguRA I7. Selección de algunos restos óseos del esqueleto prehistórico de Adakmar: cráneo y parte de la mandibula (arriba), y juego de extremidades inferiores con signos evidentes de cremación (abajo) 
Centrándonos, de seguido, ya más particularmente, en el marco geopolítico del Sahara Occidental, la primera impresión que se tiene es que el panorama aquí no difiere, de forma especial, del marcadamente austero en datos que venimos de describir, en relación a la cronología de las referencias antropológicas del Holoceno.

Simplificando los detalles, conviene tener presente que en los $266.000 \mathrm{~km}^{2}$ de superficie de este territorio hay, hasta hoy, solamente 11 dataciones absolutas efectuadas sobre restos humanos. De ellas, un conjunto de 7 -asociadas a depósitos sepulcrales no monumentales emplazados en torno a diversas sebjas próximas a la costa oceánica saharaui, y derivadas de las misiones científicas multidisciplinares que N. Petit-Maire (1979b) efectuara en torno al litoral atlántico sahariano entre 1970 y 1974 - poseen serias dudas sobre su entidad y solvencia, al haberse advertido importantes incoherencias en los valores de los análisis C14 realizados en los ańos 70 sobre referencias del litoral saharo-saheliano del NW de África, entre Cabo Juby y Cabo Verde. Una circunstancia que las convierte en seriamente problemáticas, denunciándose sus valores como altamente dudosos (Vernet, Saliège y Tous 2006, 309ss). Y otro grupo de 2 dataciones más, de ese total inicial de 11, originarias de sendos túmulos funerarios de la zona de Tifariti (Zemmur) excavados en 2005 (Brooks et al. 2009), han ofrecido valores excesivamente recientes, acaso derivados de su bajo contenido en colágeno.

Las 2 dataciones que restan de toda la serie provienen de nuestras actuaciones en el Tiris. Una de ellas, derivada de un pequeño fragmento craneal humano recuperado en un pequeño túmulo desmantelado sobre la montaña de Gleb Tinlluleg (Agüenit), analizada a partir de la fracción de apatito, aportó la fecha convencional de $3.020 \pm 30$ B.P. (Sáenz de Buruaga 2013a, 57), cuyo valor medio calibrado rondaría los 3.220 calB.P. La otra, por su parte, pertenece a un fragmento de fémur humano hallado accidentalmente en superficie, y de forma aislada, en un punto de la planicie de Duguech, al S del Tiris. Su análisis igualmente sobre la fracción de apatito ofreció la data convencional de $5.830 \pm 35$ B.P. (Sáenz de Buruaga 2017), que en valores calibrados se aproximaría a 6.638 calB.P., es decir, no excesivamente distantes del señalado en el enterramiento de Izriten.

Con todo, este es el exiguo panorama de dataciones humanas preislámicas con que contamos en el Sahara Occidental. Una base de datos mínima y más que insuficiente para intentar plantear un esbozo elemental, no ya de la evolución, sino de la configuración básica contrastada del componente humano en la Prehistoria del Holoceno.

A pesar de las dificultades y limitaciones, lancemos, no obstante, una mirada positiva. Y extraigamos que todas estas restricciones y carencias de datos cronológicos absolutos de restos humanos no hacen, si cabe, sino ensalzar aún más la valía del documento que presentamos de Adakmar ${ }^{3}$.

3 Remarcábamos al inicio de este trabajo de presentación de la inhumación de la Sebja Planicie Adakmar E-1, la trascendencia científica del descubrimiento, en la medida en que se erigía en el dato antropológico y funerario más antiguo de que disponemos del amplio espacio del Occidente del Sahara. Se impone, en consecuencia, la ejecución imperativamente de una serie rigurosa de analíticas antropo-genéticas y geo-arqueológicas especializadas. Por ello, se está tramitando actualmente el traslado temporal de los restos del esqueleto a unos laboratorios especializados europeos en los que poder llevar a cabo esas exigencias científicas. Una gestión, por otra parte, muy complicada, en términos diplomáticos, y cargada de una razonable incertidumbre, en función de la compleja situación geopolítica del
Sahara Occidental y de su difusa definición internacional como territorio "no autónomo", es decir, pendiente de descolonización, conforme a la evaluación de la ONU. Unas circunstancias adversas que invitan a pensar que, en el mejor y más favorable de los casos, deberá de recorrerse aún un largo trayecto administrativo y, por consiguiente, se acompañará el proceso de un tiempo considerable. De momento, por nuestra parte, a la conclusión de la campaña de investigaciones de otoño de 2016, procedimos a mediados de octubre a su traslado desde la Base militar de Agüenit (Sahara Occidental), en donde lo habíamos dejado a finales de febrero, a los Campamentos de Refugiados Saharauis en Tindouf (Argelia) y a su depósito en las dependencias del Ministerio de Cultura de la RASD. 
Algunas CONSIDERACiONES CRONO-CULTURALES COMPLEMENTARIAS CON EL GESTO FUNERARIO DE ADAKMAR

A la hora de describir, líneas atrás, el proceso de recuperación de los restos óseos, ya hemos incidido en la falta de cualquier referencia cultural arqueológica asociada al resto inhumado o al continente sepulcral. Ello nos incitaba a sugerir, merced a una sólida serie entrelazada de datos arqueofunararios suficientemente explicitados (posición y orientación del cadáver, tratamiento por el fuego, deposición en fosa o cubeta, etc.), su contextualización dentro de un genérico marco prehistórico postpaleolítico.

La datación directa del esqueleto y su refrendo por la fecha complementaria de un depósito de travertinos a techo, y la génesis y posición secuencial geo-climática del depósito de arenas carbonatadas en el que se practicó el enterramiento, determinan y fijan su rango temporal en torno a mediados del IX milenio calB.P., es decir, en una fase ya avanzada del Holoceno antiguo.

Mas, al margen del hecho funerario y cronológico precisos, ¿qué más pudiéramos inferir de estos datos empíricos de momento disponibles, en relación a algún aspecto propiamente sociocultural del grupo humano con el que pudiera asociarse?

En principio, ante la falta de contextualización cultural precisa que pudiera desprenderse de unas hipotéticas referencias industriales vinculadas de alguna forma al gesto funerario — en cualquier caso, aquí inexistentes_-, nos inclinamos a pensar que la inhumación de Adakmar bien pudiera correlacionarse genéricamente con las poblaciones de cazadores-recolectores pre-neolíticos del Occidente del Sahara.

No cabe duda que la mejora climática que se advierte ya desde 13.000 calB.P. y los más expresivos cambios climáticos que, a partir de 12.000 calB.P., fijarán definitivamente el inicio del Holoceno, han debido de tener su incidencia sobre la ocupación del espacio por los grupos humanos en el Occidente sahariano. No obstante, los datos materiales arqueológicos disponibles son más que puntuales, dispersos y poco consistentes, de tal manera que resulta prácticamente imposible el hacerse una idea mínimamente coherente de las antiguas poblaciones prehistóricas pre-neolíticas durante el Holoceno antiguo (ca. 12.000-7.800 calB.P).

Por su parte, la presencia de algunas lagunas sedimentarias en el proceso de evolución y conformación estratigráfica de la secuencia paleoclimática en las fases iniciales del Holoceno - tal como lo ilustraba, sin ir más lejos, la situación que aquí abordamos del depósito de Adakmar, o, por ejemplo, la advertida ańos pasados en uno de los sondeos estratigráficos efectuado en uno de los segmentos de la sebja de Emherisat (Sáenz de Buruaga 2013b, 344ss), en este mismo ambiente fisiográfico del erg de Azefal—, testimonian la complejidad y dificultad de obtener informaciones estables, es decir, en marcos contextualizados, de ese tramo inicial del Holoceno y de las características de su poblamiento y, lógicamente, de sus expresiones culturales.

En este sentido, en nuestro entorno más o menos cercano, únicamente se ha mencionado - $y$ no sin reservas: al encontrarse las evidencias frecuentemente sin contexto depositacional seguro, y mezclados sus efectivos con series industriales de distinta caracterización cultural y, en consecuencia, cronológica - algún testimonio del Epipaleolítico avanzado en el NW de Mauritania (Vernet 2004) y, en función de la potencial significación otorgada a algún supuesto "fósil director», se ha proyectado su extensión territorial, merced a la identificación en diferentes áreas de las denominadas "puntas de Foum Arguin» — cuyos espacios físicos de asiento, por lo normal, han sido reocupados por grupos neolíticos y sus evidencias materiales (insistamos nuevamente) se han visto indefectiblemente mezcladas por las especiales circunstancias erosivas y de severa alteración que conlleva el medio desértico-, a un amplio territorio del Occidente del Sahara: desde el Oued Drâa ( $\mathrm{S}$ de 
Marruecos), por el N, al golfo de Arguin (NW de Mauritania), por el S, y desde el litoral atlántico, por el W, a las estribaciones montañosas occidentales de los relieves del Adrar (Mauritania), por el E. Según R. Vernet, su definidor, la horquilla cronológica de la «cultura epipaleolítica de Foum Arguin» debería extenderse, al menos, en términos convencionales, entre 7.000 y 6.000 B.P, es decir, en valores calibrados, fundamentalmente a lo largo del VIII milenio calB.P. (Vernet 2007, 72). Y, en relación con este episodio cultural, la sepultura de Izriten, al N de Tarfaya (Marruecos), a la que líneas previas hemos hecho alusión, y cuya cronología se sitúa en la transición del VIII al VII milenio calB.P., debería vincularse con ello, al haberse recuperado en el área inmediata materiales líticos del tipo del epipaleolítico de Foum Arguin ${ }^{1}$.

En el caso nuestro, la datación de la sepultura de Adakmar acaso bien pudiera representar un evento previo al de la "cultura del Foum Arguin", asociado asimismo con algunas expresiones culturales del Epipaleolítico del Occidente del Sahara.

Por último, y si bien colateralmente, no queremos concluir este texto sin dejar de mencionar y remarcar las excepcionales circunstancias que han debido rodear al esqueleto de Adakmar para preservarlo y facilitar su conservación hasta nuestros días.

Por definición, la conservación de restos humanos resulta extremadamente rara en contextos arenosos extensos, como en el que se descubrió nuestra sepultura (fig. 18). De hecho, al carácter ya ácido de los suelos, se suman aquí como activos agentes de deterioro los constantes y fuertes vientos cargados de partículas terrosas en suspensión, las episódicas y violentas lluvias que, de cadencia esporádica, generan severas acciones erosivas de desmantelamiento y arrastre de los depósitos sedimentarios, y lógicamente la exposición a la intensa insolación y a los marcadas oscilacioneses diurnas y estacionales de las temperaturas. Unos agentes atmosféricos marcadamente adversos para la conservación de los restos óseos que, en el mejor de los casos, aseguran difícilmente la presencia residual e inusual de los testimonios antropológicos: en cualquiera de los casos, altamente degradados, frágiles y francamente muy escasos en número.

$\mathrm{Y}$, junto a esta particular coyuntura meteorológica en el presente, debe de retenerse el excepcional ambiente de preservación acaecido en el pasado, a través de un activo proceso de fosilización iniciado tras el rápido enterramiento y cubrición por la tierra del cadáver. Y, en paralelo con ello, el no haber sufrido, en todo el tiempo, accidentes o alteraciones de envergadura por agentes biológicos y, especialmente, por la incidencia de depredadores, merced a su exposición superficial. Ciertamente, con todas estas potenciales anomalías, podemos afirmar que el hecho de su conservación resulta cuando menos sorprendente, sino insólito.

Con todo, pues, hemos tenido la fortuna de documentar los restos de un esqueleto humano, bastante bien conservados, en contexto sepulcral y de una parte de un singular ritual funerario a él asociado. Todo ello, asociado cronológicamente, a un momento de trascendental importancia para conocer el origen del poblamiento humano del Occidente del Sahara en las fases iniciales del Holoceno.

\footnotetext{
4 Una presencia tecno-tipológica del Epipaleolítico, por otra parte, que ya había sido denunciada años atrás es ese ámbito espacial de la cuenca litoral de Tarfaya en forma de facies industrial original (Grébénart 1975b),
}

concretada y definida ulteriormente como «Taoulektiense» (Onrubia-Pintado y Ballouche 1996), y cuyas características se han valorado como próximas a las del epipaleolítico de Foum Arguin (Vernet 2007, 83). 


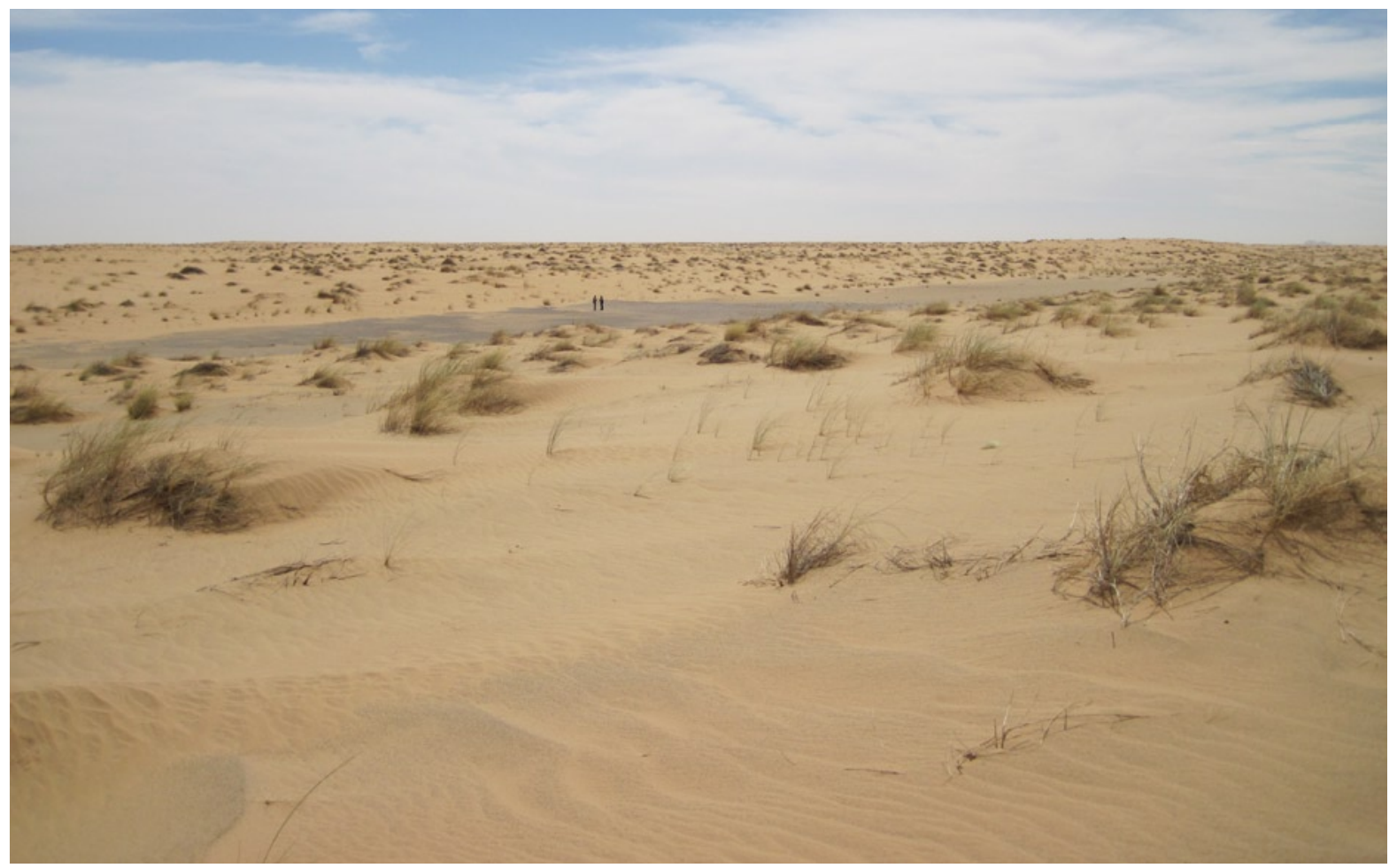

Figura i 8. Depósitos actuales de dunas del erg de Azefal y depresión en cuyo fondo se encuentra la Sebja Planicie Adakmar E-1. El afortunado hallazgo en ella de los restos humanos supone un dato de excepcional relevancia cientifica, al tratarse de la referencia antropológica y sepulcral más antigua del Holoceno en el Occidente del Sahara

\section{BiBLIOGRAFÍA}

Aoudia-Chouakri, L., 2013, Pratiques funéraires complexes: réévaluation archéo-anthropologique des contextes ibéromaurisiens et capsiens (paléolithique supérieur et épipaléolithique, Afrique du Nord-Ouest). Sciences agricoles, Bordeaux: Université Sciences et Technologies-Bordeaux I.

Aumassip, G., 1984, «Le site de Ti-n-Hanakaten et la néolithisation sur les marges orientales du Sahara central», Cahiers ORSTOM XIV/2, 189-212.

Aumassip, G., Heim, J.-L., 1989, «Les squelettes néolithiques de Tin Hanakaten, Tassili N’Ajjer, Algérie», C. R. Académie Sciences Paris 309/III, 187-190.

Brooks, N., Clarke, J., Garfi, S., Pirie, A., 2009, «The archaeology of the Western Sahara: results of environmental and archaeological reconnaissance», Antiquity 83/322, 918-934.

Dutour, O., Petit-Maire, N., 1996, «Place des restes humains de la dune d'Izriten parmi les populations holocènes du littoral atlantique nord-africain», en: J. Riser (ed.), Le Bassin de Tarfaya (Maroc Atlantique, 28. ${ }^{\circ}$ Nord), Paris: L'Harmattan, 137-146.

El Hajraoui, M.A., Nespoulet, R., Debénath, A., Dibble, H. L., 2012, Préhistoire de la région de RabatTémara, Villes et sites archéologiques du Maroc (VESAM) III, Rabat: Ministère de la Culture, Royaume de Maroc. 
GrébÉnART, D., 1975a, «Cenotaphe et inhumations épipaléolithiques de la nécropole d'Izriten (Sahara Atlantique)", Libyca 22, 193-200.

—, 1975b, «Matériaux pour l'étude de l'Épipaléolithique et du Néolithique du littoral atlantique saharien du Maroc», Actes du Colloque sur l'Épipaléolithique, (Aix, 1972), Paris: CNRS, 151-186.

Onrubia-Pintado, J., Ballouche, A., 1996, «Les industries épipaléolithiques de Taoulekt. Les sites TR-3 et TR-5», en: J. Riser (ed.), Le Bassin de Tarfaya (Maroc Atlantique, 28. ${ }^{\circ}$ Nord), Paris: L'Harmattan, 153-190.

Petit-Maire, N., 1979a, "Cadre écologique et peuplement humain: le littoral ouest-saharien depuis 10.000 ans", L'Anthropologie 83/1, 69-82.

—, 1979b, Le Sahara Atlantique à l'Holocène. Peuplement et Écologie, Alger: Mémoires du Centre de Recherches Anthropologiques, Préhistoriques et Ethnographiques XVIII.

Petit-Maire, N., Charon, M., Ortlieb, L., 1979, «La dune d'Izriten», en: N. Petit-Maire (dir.), Le Sahara Atlantique à l'Holocène. Peuplement et Écologie, Alger: Mémoires du Centre de Recherches Anthropologiques, Préhistoriques et Ethnographiques XVIII, 17-34.

Petit-Maire, N., Dutour, O., 1996, «Les restes humains d'Izriten-Les premières découvertes», en: J. Riser (ed.), Le Bassin de Tarfaya (Maroc Atlantique, 28. ${ }^{\circ}$ Nord), Paris: L'Harmattan, 121-128.

Sáenz de Buruaga, A., 2008, Contribución al conocimiento del pasado cultural del Tiris, Sahara Occidental. Inventario del patrimonio arqueológico, 2005-2007, Vitoria-Gasteiz: Servicio Central de Publicaciones del Gobierno Vasco.

—, 2010, Pinceladas de un desierto vivo desde la región del Tiris, en las tierras libres del Sahara Occidental, Vitoria-Gasteiz: Servicio Central de Publicaciones del Gobierno Vasco.

—, 2013a, «Note préliminaire sur la découverte de tumulus "géants" dans l'erg Azefal (Sahara occidental)», Sahara 24, 47-64.

—, 2013b, «Sobre la función del “Área de Reserva Medioambiental” del Azefal (S.E. del Sahara Occidental) en el Holoceno y la presencia de ciertas estructuras "megatumulares"», Sautuola XVIII, 339-353.

—, 2014, Nuevas aportaciones al conocimiento del pasado cultural del Tiris, Sahara Occidental. Inventario del patrimonio arqueológico, 2008-2011, Vitoria-Gasteiz: Servicio Central de Publicaciones del Gobierno Vasco.

—, 2017, «Un resto humano del inicio del VI milenio en el sector meridional del Tiris, en el extremo SE del Sahara Occidental», en: J. Fernández Eraso, M. García Diez, J.A. Mujika, A., Arrizabalaga (eds.), Homenaje a Lydia Zapata Peña, Vitoria-Gasteiz: Servicio Editorial UPV/EHU, (en prensa).

Sáenz de buruaga, A., Arruabarena, J.M. 2015, Un recorrido por las imágenes pintadas y grabadas del Tiris. Arte rupestre y territorio en el extremo suroriental del Sahara Occidental, Vitoria-Gasteiz: Asociación Vasco-Saharaui de la Evolución Cultural.

Sereno, P.C., Garcea, E.A.A., Jousse, H., Stojanowski, C.M., Saliège, J.-F., et al., 2008, «Lakeside Cemeteries in the Sahara: 5000 Years of Holocene Population and Environmental Change» PloS ONE 3(8): e2995, doi: 10.1371/journal.pone.0002995

Vernet, R., 2004, «L'industrie de Foum Arguin (nord-ouest de la Mauritanie). Une culture épipaléolithique de l'ouest saharien, entre cap Juby et cap Timiris», Sahara 15, 75-82.

—, 2007, Le golfe d'Arguin de la préhistoire à l'historire, Nouakchott: Collection PNBA 3.

Vernet, R., Saliège, J.-F., Tous, Ph., 2006, "Chronologie radiocarbone critique du littoral saharo-sahélien à l'Holocène», en: Senegalia. Études sur le patrimoine ouest-africain. Hommage à Guy Thilmans, Saint-Maur-des-Fossés: Sépia, 308-318. 